\title{
LA POLÍTICA AGRARIA COMÚN EN EL ALTO GUADIANA: EVOLUCIÓN DE RECURSOS HÍDRICOS Y DE CULTIVOS
}

\author{
Y.SANJUAN \\ Instituto Pirenaico de Ecología, CSIC, Campus de Aula Dei, \\ Apartado 13.034, 50080 Zaragoza, España.
}

RESUMEN. Existen claras relaciones entre las ayudas procedentes de la Política Agraria Común (PAC) y la sobreexplotación de acuíferos en la cuenca alta del río Guadiana. Históricamente las ayudas de Europa a la agricultura han estado ligadas a la producción, lo que ha ocasionado, en los 169 municipios pertenecientes a la zona de estudio, una fuerte tendencia a la expansión del regadio. La implantación del Pago Único en 2003 implica un desacoplamiento de las ayudas a la producción, pasando a cobrar, los perceptores de las ayudas, un subsidio equivalente a la media de lo percibido durante los tres últimos años, es decir que a partir de 2003 los pagos se mantienen aunque la producción sea nula. No obstante, aún existen muchos pagos ligados a la producción, conocidos como pagos acoplados (básicamente los asociados a la ganadería, cultivos leñosos, cultivos herbáceos y regadio). Estos son los que tienen una mayor capacidad para afectar al medio ambiente y son, por lo tanto, los que se han tenido en cuenta en este estudio (salvo la ganadería por no relacionarse directamente con la sobreexplotación de acuíferos).

Para realizar este trabajo se ha utilizado el programa ArcGis, superponiendo o comparando capas de distintas temáticas: Espacios Naturales Protegidos, Acuíferos Sobreexplotados y Zonas Vulnerables a la Contaminación por Nitratos en el Alto Guadiana, el porcentaje de hectáreas en regadío en los distintos términos municipales, la superficie en regadio dedicada a cultivos herbáceos y cultivos leñosos, y por último, los niveles de ayudas de la Política Agraria Común (PAC) en cada uno de los sectores elegidos y para cada uno de los municipios del Alto Guadiana, en el año 2009.

Entre las conclusiones destaca el hecho de que los municipios con mayor porcentaje de superficie de regadío, especialmente viñedos, reciben los mayores niveles de ayudas a pesar de utilizar agua de acuíferos sobreexplotados. En cambio, las ayudas a la agricultura ecológica son escasas al igual que la compensación por renta de acuíferos. Esto sugiere que las ayudas de la PAC acopladas a cultivos leñosos (fundamentalmente el viñedo) y herbáceos actúan en detrimento de la calidad ambiental de la zona de estudio, muy especialmente de los recursos hídricos. Como nota positiva se ha observado que un alto porcentaje de 
uno de los dos pilares de la PAC (fondos FEADER) va destinado a los ejes de inversión de Medio Ambiente y Desarrollo Rural.

\section{The Common Agricultural Policy in the Upper Guadiana: evolution of water resources and crops}

ABSTRACT. There are clear links between supports from the Common Agricultural Policy (CAP) and the overexploitation of aquifers in the upper basin of the Guadiana River. Historically, European supports to agriculture have been linked to the production, which has resulted in the 169 municipalities in the study area, a strong trend towards the expansion of irrigation lands. The implementation of the Single Payment in 2003 implies a decoupling of production supports, going to charge the beneficiaries of supports a subsidy equal to the average of that perceived during the last three years, i.e. from 2003 payments are maintained even though production is zero. However, there are still many payments linked to production, known as coupled payments (primarily those associated with livestock, woody crops, arable crops and irrigated land). These are the ones with higher capacity to affect the environment, and therefore they are which have been considered in this study (except livestock, no directly related to overexploitation of aquifers).

To make this paper, ArcGis program has been used, superimposing or comparing different thematic layers: Protected areas, overexploited aquifers and vulnerable areas to nitrates pollution in the Upper Guadiana, the percentage of irrigated hectares in several municipalities, the irrigated area devoted to arable crops and woody crops, and finally support levels of the Common Agricultural Policy (CAP) in each of the selected sectors and for each of the municipalities in the Upper Guadiana in 2009.

It is noteworthy that the municipalities with the highest percentage of irrigated area, especially vineyard, receive higher levels of subsidies, despite of using water from overexploited aquifers. In contrast, supports to organic farming are scarce as compensation income from aquifers. This suggests that CAP subsides coupled to woody crops (mainly the vineyard) and herbaceous crops are detrimental for the environmental quality of the study area, especially water resources. As a positive factor it was found that a percentage of one of the two pillars of the CAP (EAFRD) is devoted for investment axes of Environment and Rural Development.

Palabras clave: recursos hídricos, sobreexplotación de acuíferos, regadío, Política Agraria Comunitaria, Alto Guadiana.

Key words: water resources, overexploitation of aquifers, irrigated lands, Common Agricultural Policy, Upper Guadiana.

* Correspondencia: Instituto Pirenaico de Ecología, CSIC, Campus de Aula Dei, Apartado 13.034, 50080 Zaragoza, España. E-mail: ysanjuan@ipe.csic.es 


\section{Introducción}

El estado del medio hídrico y de los suelos depende de las complejas interacciones entre los usos del suelo y de las características del medio, de su historia y de los tipos de incentivos que sus habitantes reciben en relación con cada tipo de uso. Dos tipos importantes de incentivos son los mercados y las subvenciones en el marco de determinadas políticas públicas.

Sin embargo, es bien conocido que los distintos usos del suelo pueden implicar diferentes problemas ambientales. Uno de los casos paradigmáticos es la cuenca alta del río Guadiana, en Castilla-La Mancha, donde la agricultura de regadío ha traído consigo la explotación intensiva de recursos hídricos y la contaminación por nitratos de origen agrario (Cobelas et al., 2001). La consecuencia más importante ha sido el deterioro del Parque Nacional de las Tablas de Daimiel (PNTD) (Cirujano et al., 1976; Conan et al., 2003) y la dudosa sostenibilidad de las actividades agrícolas en el marco actual de explotación (López-Sanz, 1999; Fornés et al., 2000).

España, con casi un $80 \%$ del territorio dedicado a la agricultura y a la ganadería, es el segundo país de la Unión Europea (UE) que recibe más ayudas de la Política Agraria Común (PAC). Ésta viene determinando el modelo mayoritario de gestión agraria, particularmente en España desde la entrada en vigor de su adhesión a la UE en 1986. Para entender la importancia de la PAC en la evolución de actividad agraria basta señalar que representa el $42 \%$ del presupuesto total de la UE, con una inversión de 55000 millones de euros en 2009.

Actualmente la PAC se estructura en dos fondos específicos (conocidos comúnmente como los dos pilares de la PAC), FEAGA y FEADER:

- El Fondo Europeo de Garantía Agraria (FEAGA) tiene como objetivo garantizar los abastecimientos de productos agrícolas y ganaderos, y a su vez determinados ingresos complementarios a los que los agricultores obtienen del mercado.

- El Fondo Europeo Agrícola de Desarrollo Rural (FEADER), está destinado a promover la modernización de la actividad agraria, respetando al medio ambiente, así como la diversificación económica del medio rural. Está cofinanciado por los Estados Miembros y se divide en tres ejes temáticos: 1. Competitividad de explotaciones agrícolas y ganaderas, 2. Mejora del medio ambiente, 3 . Diversificación y calidad de vida en el medio rural; además existe un cuarto eje metodológico con un enfoque similar al de los grupos LEADER (Iniciativa de la Unión Europea para el desarrollo rural), basado en el desarrollo rural.

El volumen económico de estos dos fondos-pilares de la PAC es bastante desigual. Los pagos destinados al FEAGA (Pilar I) reciben casi el 78\% del presupuesto total de la PAC, mientras que el FEADER (Pilar II) cuenta con poco más de un $22 \%$ de los fondos disponibles (SEO/Birdlife y WWF, 2010a). 
Algunos estudios analizan, a nivel de toda España, las relaciones existentes entre las ayudas de la PAC y algunos aspectos ambientales del uso del suelo y de los recursos hídricos (SEO/Birdlife y WWF, 2010b), concluyendo que la sostenibilidad en la agricultura sigue siendo una parte minoritaria de la PAC en términos de presupuesto e implementación. Por otro lado, todavía los modelos agrarios más productivos y rentables, con importantes impactos sobre el medio ambiente son los que perciben mayores ayudas (López Sanz, 1999).

Este trabajo analiza la situación medioambiental de la cuenca alta del Guadiana en relación con las ayudas de la PAC, en una zona con gran valor ambiental y, al mismo tiempo, con una gran complejidad socioeconómica del uso del agua. Para ello se analiza la relación entre las ayudas de la PAC (pagos tanto del Pilar I como del Pilar II) y los problemas de conservación de los recursos naturales (acuíferos sobreexplotados y Zonas Vulnerables a la Contaminación por Nitratos, ZVCN). Mediante diferentes aproximaciones se comprueba hacia dónde se dirigen las mayores ayudas (cultivos intensivos o extensivos) y su grado de implicación en la evolución de determinados parámetros medioambientales. Como año de estudio se ha tomado el 2009, por ser el último con datos disponibles de la PAC en Castilla-La Mancha al comienzo del estudio. Igualmente se pretende contribuir al debate ya en marcha sobre el futuro de la PAC de cara a la reforma que tendrá lugar en 2013.

\section{La zona de estudio: Cuenca del Alto Guadiana}

El río Guadiana drena 67733 km² en la sub-meseta sur de la Península Ibérica entre los Montes de Toledo al norte y Sierra Morena al Sur, limitando hacia el este/sureste con las estribaciones del Sistema Ibérico y el dominio Prebético. La cuenca alta del Guadiana ocupa una extensión aproximada de $18900 \mathrm{~km}^{2}$ incluyendo términos municipales de cuatro provincias de Castilla-La Mancha (Tabla 1) (Fig. 1). Comprende la parte superior del río Guadiana hasta el río Jabalón, incluido éste, así como las cuencas de los ríos Cigüela y Záncara. Sus límites topográficos están muy poco definidos, dada la planitud casi general del relieve y la ausencia de auténticas divisorias, entre las que destaca la sierra de Altomira, al noroeste. Las áreas más bajas se localizan a 550 m s.n.m., si bien la altitud predominante está en torno a 600-700 m s.n.m.

Tabla 1. UU.HH del Alto Guadiana.

\begin{tabular}{|c|c|}
\hline UNIDADES HIDROGEOLÓGICAS DEL ALTO GUADIANA \\
\hline 04.01 & Sierra de Altomira \\
\hline 04.02 & Lillo Quintanar \\
\hline 04.03 & Consuegra-Villacañas \\
\hline 04.04 & Mancha Occidental \\
\hline 04.05 & Ciudad Real \\
\hline 04.06 & Campo de Montiel \\
\hline
\end{tabular}

Fuente: CHG, 2008. 


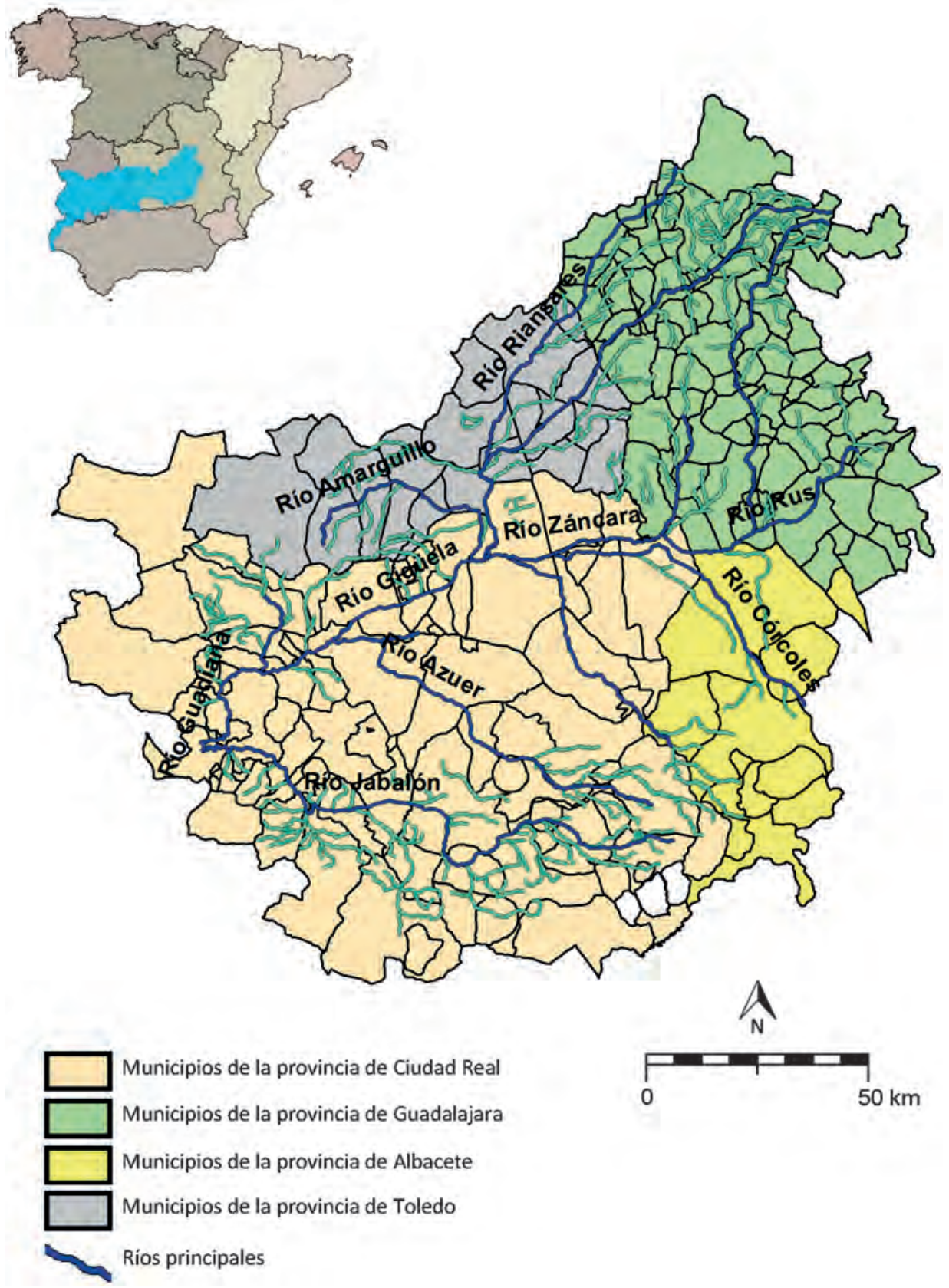

Figura 1. Localización de la zona de estudio. Elaboración propia a partir de CHG (2009b). 
Desde el punto de vista geológico, el Alto Guadiana se instala en la depresión terciaria del Tajo-Guadiana, formada como consecuencia del plegamiento alpino y de las deformaciones que este último produjo en el zócalo herciniano. La depresión se rellenó de sedimentos oligocenos, miocenos y pliocenos (calizas y arcillas arenosas) que conservan su horizontalidad original. Particularmente importante es la presencia de calizas jurásicas y cretácicas que están muy poco deformadas y que corresponden a la sedimentación en el borde marino del zócalo paleozoico. Este último, que forma el basamento de la zona de estudio, está compuesto fundamentalmente por gneises, esquistos y granitos.

El clima de la zona es de tipo mediterráneo continentalizado con una estación seca bien definida y oscilaciones térmicas muy marcadas. La precipitación media anual para 60 estaciones meteorológicas entre octubre de 1956 y septiembre de 1991 varía entre 326 mm (año hidrogeológico 1982-83) y 642 mm (1968-69), según las estimaciones de Burke et al. (1999), con una variabilidad espacial relativamente alta. La mayor parte de la zona de estudio recibe entre 400 y $600 \mathrm{~mm}$, si bien los registros medios descienden por debajo de $400 \mathrm{~mm}$ en la confluencia entre los ríos Guadiana y Cigüela. Las lluvias se producen sobre todo en invierno, primavera y otoño con un fuerte descenso estival. La temperatura media anual está entre 13 y $15^{\circ} \mathrm{C}$. La evapotranspiración potencial anual oscila entre 800 y $900 \mathrm{~mm}$ (Conan et al., 2003).

Por otra parte, el área objeto de estudio comprende 218 entidades de población distribuidas en 169 municipios coincidentes con los incluidos en el Plan Especial del Alto Guadiana, PEAG (CHG, 2008) (Fig. 1).

\subsection{Los recursos hídricos}

El Alto Guadiana se caracteriza hidrológicamente por una significativa interacción entre las aguas superficiales y las subterráneas, debido a la abundancia de formaciones geológicas permeables, principalmente calcáreas, y a su relieve poco accidentado. Estas condiciones propiciaron una de las principales singularidades de esta zona semiárida: la presencia de numerosos humedales (existiendo más de 100 en la cuenca alta del Guadiana) entre los que destacan las Tablas de Daimiel y las Lagunas de Ruidera.

En el Alto Guadiana se han identificado 6 Unidades Hidrogeológicas (UU.HH) (Tabla 1) de importancia variable en función de los recursos existentes y de la explotación de los mismos. Estas Unidades corresponden a dos tipos fundamentales de acuíferos:

- Predominantemente permeables por fisuración o karstificación $(01,02,04,05,06)$.

- Permeables por porosidad intergranular (03).

De las unidades hidrogeológicas citadas, la U.H. 0.4.0.4 (Acuífero 23 antiguo) Mancha Occidental, y la U.H. 04.06 (Acuífero 24 antiguo) - Campo de Montiel, sufren una grave situación de sobreexplotación (Fig. 2), como consecuencia de las extracciones llevadas a cabo desde mediados de los años 70 destinadas, en su mayor parte, a regadíos. Esto ha llevado a la ruptura de la conexión entre los niveles freáticos y los humedales superficiales, (alguno de ellos de gran importancia ecológica como las Tablas 

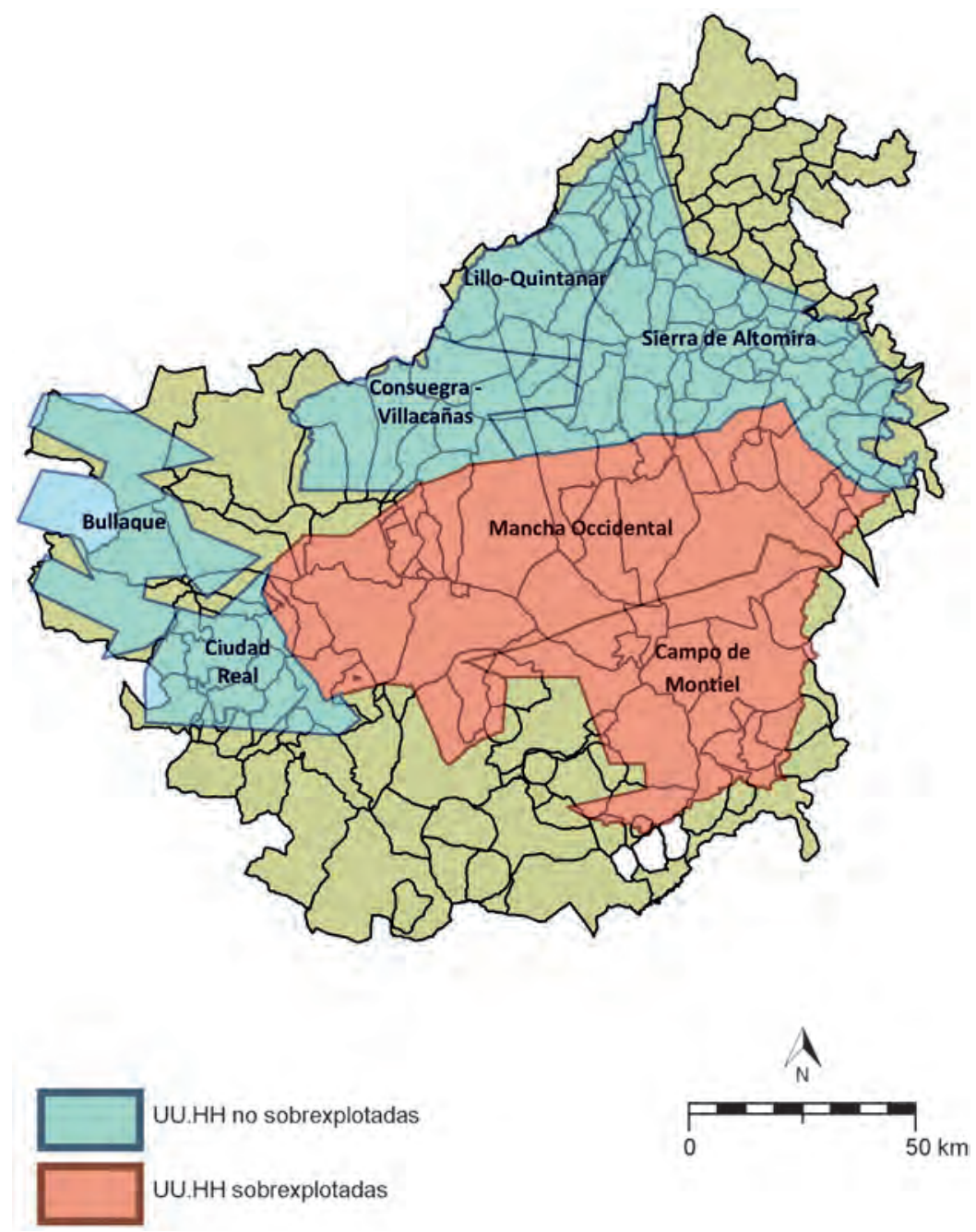

Figura 2. Acuíferos sobreexplotados. Elaboración propia a partir de datos del MARM (2010) y de la CHG (2009b).

de Daimiel), incluso se ha llegado a perder el caudal superficial en el río Guadiana en los llamados Ojos de Guadiana, el aliviadero superficial del acuífero 23, que desde el año 1984 no produce flujo superficial. Los ríos de la zona de estudio presentan caudales específicos inferiores a $11 \mathrm{~s}^{-1} \mathrm{~km}^{-2}$.

El especial funcionamiento hidrogeológico del Alto Guadiana y su importancia medioambiental se pone de manifiesto en la existencia de 128 humedales que ocupan una superficie total de 9412 ha $(\mathrm{CHG}, 2008)$. Más del 10\% de la superficie de humedales ha desaparecido en las últimas décadas, aunque esta cifra podría acercarse al $20 \%$ si 


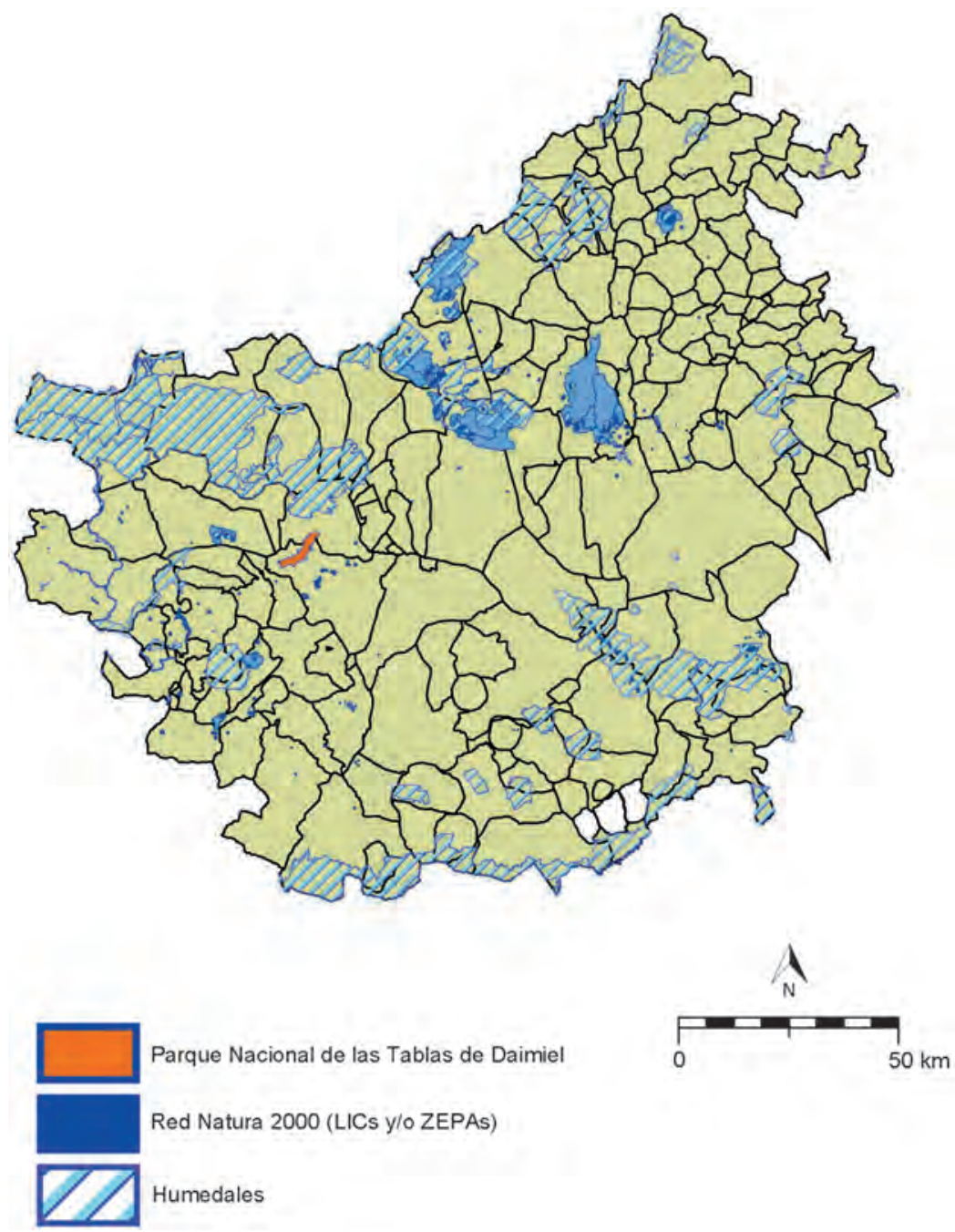

Figura 3. Espacios Naturales Protegidos en el Alto Guadiana. Elaboración propia a partir de datos de MARM (2010) y de la CHG (2009b).

se contabilizaran adecuadamente las zonas de playa y vegetación de los márgenes, ya desaparecidos. La Fig. 3 muestra la localización de los humedales, así como otros espacios naturales protegidos.

Tanto los caudales superficiales como los niveles de los acuíferos subterráneos han experimentado un fuerte descenso desde la década de 1980, a la vez que se producía un deterioro de la calidad de los recursos hídricos (Burke et al., 1999; Berzas et al., 2000). El caso más destacado corresponde al PNTD, cuya superficie inundada se ha reducido de 15-20 km² a menos de $1 \mathrm{~km}^{2}$ (Fornés et al., 2000). El Parque, creado en 1973, ha 
experimentado grandes cambios debido tanto a una progresiva desecación, que incluyó la construcción de ocho canales de drenaje, como a la destrucción de pequeñas presas de molinos para evitar la retención de agua (Cobelas et al., 1996). Pero el factor más importante de la contracción superficial ha sido la rápida expansión del regadío, basado sobre todo, en la extracción de agua subterránea (Llamas, 1988). Hacia mediados de la década de 1980 el acuífero mostraba claras señales de sobreexplotación, con un acusado descenso del nivel de agua de hasta 40 m (Fornés et al., 2000). En 1994 el acuífero se consideró oficialmente sobreexplotado (Cobelas et al., 1996). Esta evolución ha tenido consecuencias dramáticas para la flora y fauna características del PNTD, con un claro descenso en la riqueza de especies, sobre todo plantas hidrófitas ligadas a aguas permanentes (Cirujano et al., 1996). Según Conan et al. (2003) la recarga anual media del acuífero es de 200 a $300 \mathrm{hm}^{3}$, mientras que la extracción pasó de $150 \mathrm{hm}^{3}$ en 1974 a $590 \mathrm{hm}^{3}$ en 1987. A todo esto se añadió la combustión espontánea de los Ojos del Guadiana (García Rodríguez y Llamas, 1992).

Con el fin de restaurar la funcionalidad del PNTD se inició en 1988 un Plan de Regeneración Hidrológica que perseguía aumentar la superficie inundada. El Plan consistía en la construcción de dos presas dentro del PNTD, y, sobre todo, el trasvase de entre 1.5 y $15 \mathrm{hm}^{3}$ de agua anuales (Peinado et al., 2009) desde la cuenca del río Tajo hacia el río Cigüela a través del acueducto del trasvase Tajo-Segura (Cirujano et al. 1996, Fornés et al., 2000). Sin embargo, a pesar de ello la evolución del PNTD ha empeorado progresivamente, debido a la infiltración que experimenta el agua en el río Cigüela, al atravesar terrenos cársticos (Sanz Donaire et al., 1994). La Confederación Hidrográfica del Guadiana (CHG) ha llegado a plantearse la posibilidad de aportar hacia el Parque aguas residuales tratadas en depuradoras (Navarro et al., 2011).

Por otra parte, en el Alto Guadiana hay 5 zonas declaradas como Zonas Vulnerables a la Contaminación por Nitratos (ZVCN), Campo de Montiel, Lillo-Quintanar-Ocaña, Mancha Occidental, Campo de Calatrava y La Mancha Oriental, que incluye únicamente dos municipios del Alto Guadiana (Fig. 4). Estos nitratos son fundamentalmente de origen agrario y contribuyen a la degradación de la calidad de las aguas subterráneas.

Actualmente, la mayor presión sobre los recursos hídricos procede de las extracciones destinadas a satisfacer las demandas del regadío (93\%), cuya fuente principal de suministro son las aguas subterráneas. Las detracciones para abastecimiento (5.8\%) y para uso industrial $(0.2 \%)$ son mucho menos significativas (CHG, 2009a). En la Fig. 5 se muestra la localización de los pozos destinados a abastecer tierras de cultivo de regadío.

Muchos de los pozos de la zona son ilegales. Según WWF España et al. (2006), existen "más de 24000 captaciones sin concesión frente a las más de 16000 legales". A ello hay que añadir que la suma del volumen total de derechos de las concesiones legales supone más del doble del volumen de agua renovable del acuífero. El grado de incumplimiento del régimen anual de explotación también es elevado y responsable de cerca del $50 \%$ del volumen anual extraído de forma irregular. 

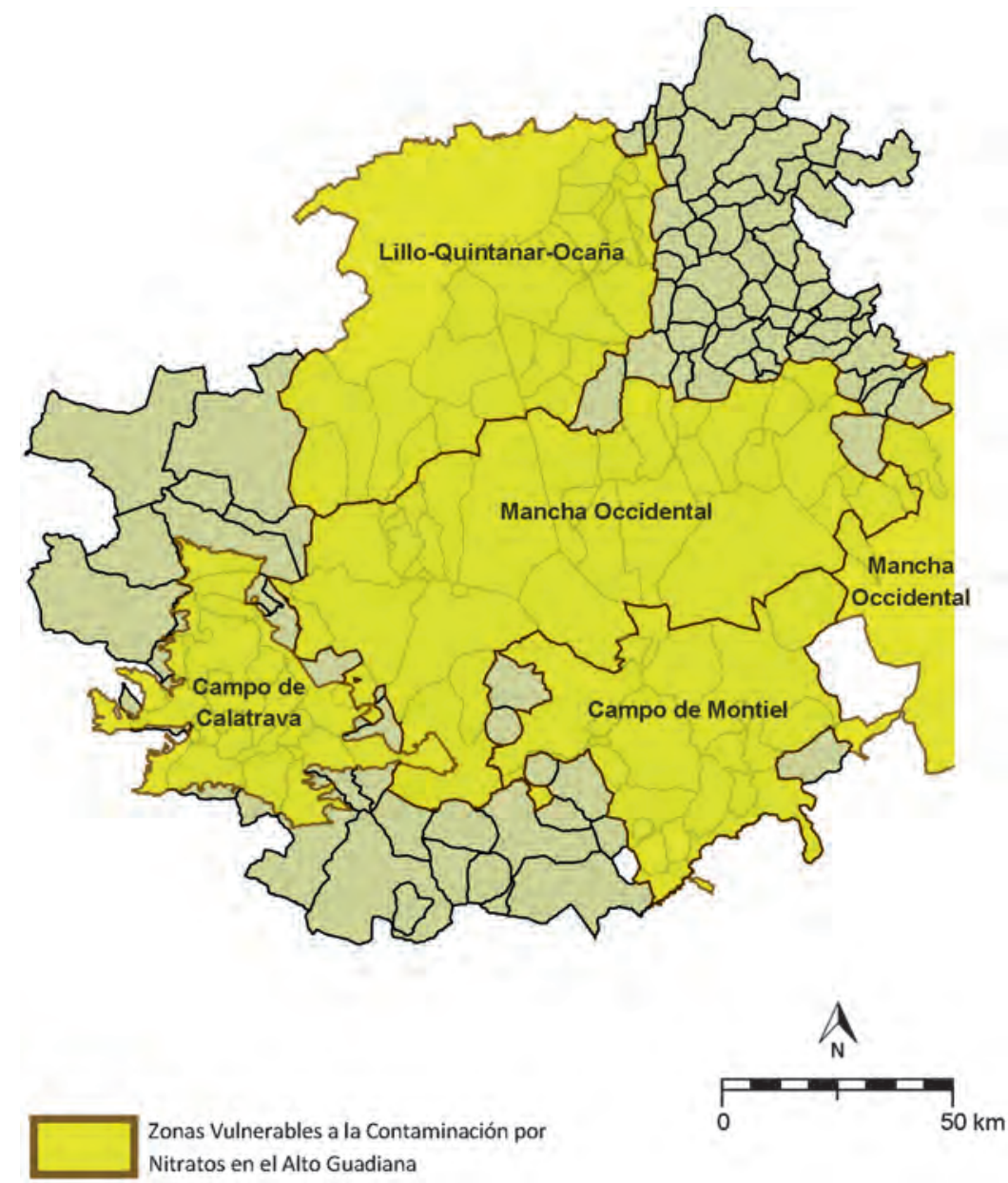

Figura 4. Zonas Vulnerables a la Contaminación por Nitratos. Elaboración propia a partir de datos de MARM (2010) y de la CHG (2009b).

\subsection{El uso agrario del suelo}

El principal uso del suelo en la zona de estudio es el agrario (con el $70 \%$ de la superficie del Alto Guadiana dedicada a tierras de cultivo).

Según a los datos del Ministerio de Agricultura, Alimentación y Medio Ambiente (MARM), la zona de estudio contaba, en el año 2009, con un total de 2469617 ha cultivadas. Tres municipios pertenecientes a la provincia de Ciudad Real, Ruidera, Arenales de San Gregorio y Llanos del Caudillo, no han podido ser analizados por falta de datos.

La superficie de regadío presenta un continuo crecimiento (Ruíz Pulpón, 2007). En 2001 la superficie dedicada al regadío en el Alto Guadiana era de 262868 ha (CHG, 


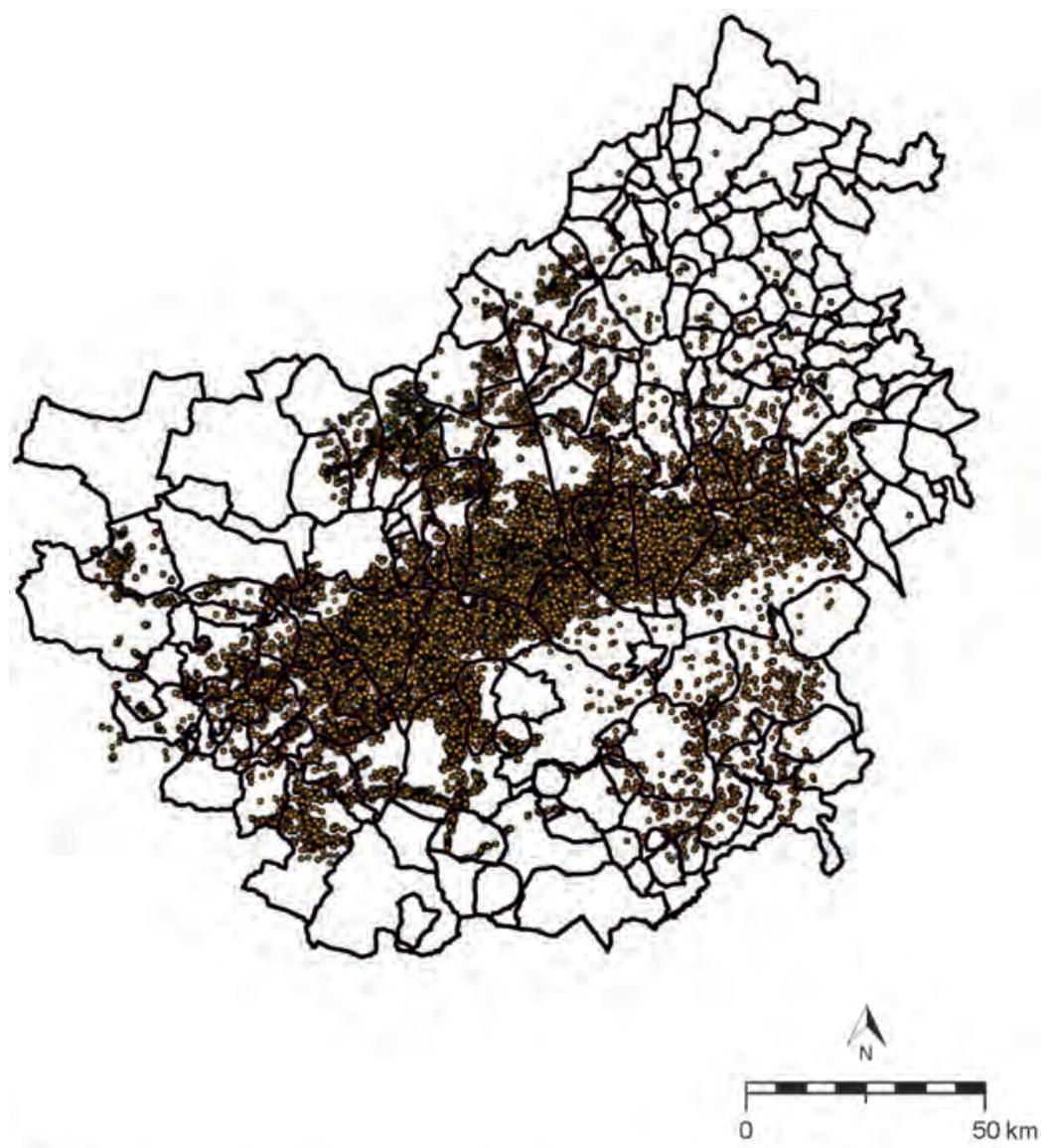

Pozos utilizados para el abastecimiento del regadío

Figura 5. Localización de pozos para abastecimiento del regadío. Fuente: Modificado a partir de $C H G$ (2009a) y de CHG (2009b).

2008), lo que implica un crecimiento en 54783 ha en 8 años. Asimismo, el origen subterráneo del agua es el predominante en el Alto Guadiana ya que, según datos de 2001, se utiliza en cerca de 240000 ha. En la Fig. 6 se puede ver el porcentaje de superficie agraria útil ocupado por hectáreas en regadío en cada uno de los municipios pertenecientes al Alto Guadiana, destacando Daimiel, Alcázar de San Juan, Manzanares o Arenas de San Juan entre otros por la gran proporción que en ellos representa el regadío, localizados en el eje central del área de estudio, coincidiendo con la presencia del mayor número de pozos. Según Martínez Vega et al. (1995) el municipio de Alcázar de San Juan llegó a consumir en 1987 un tercio del total del agua extraída del acuífero. 

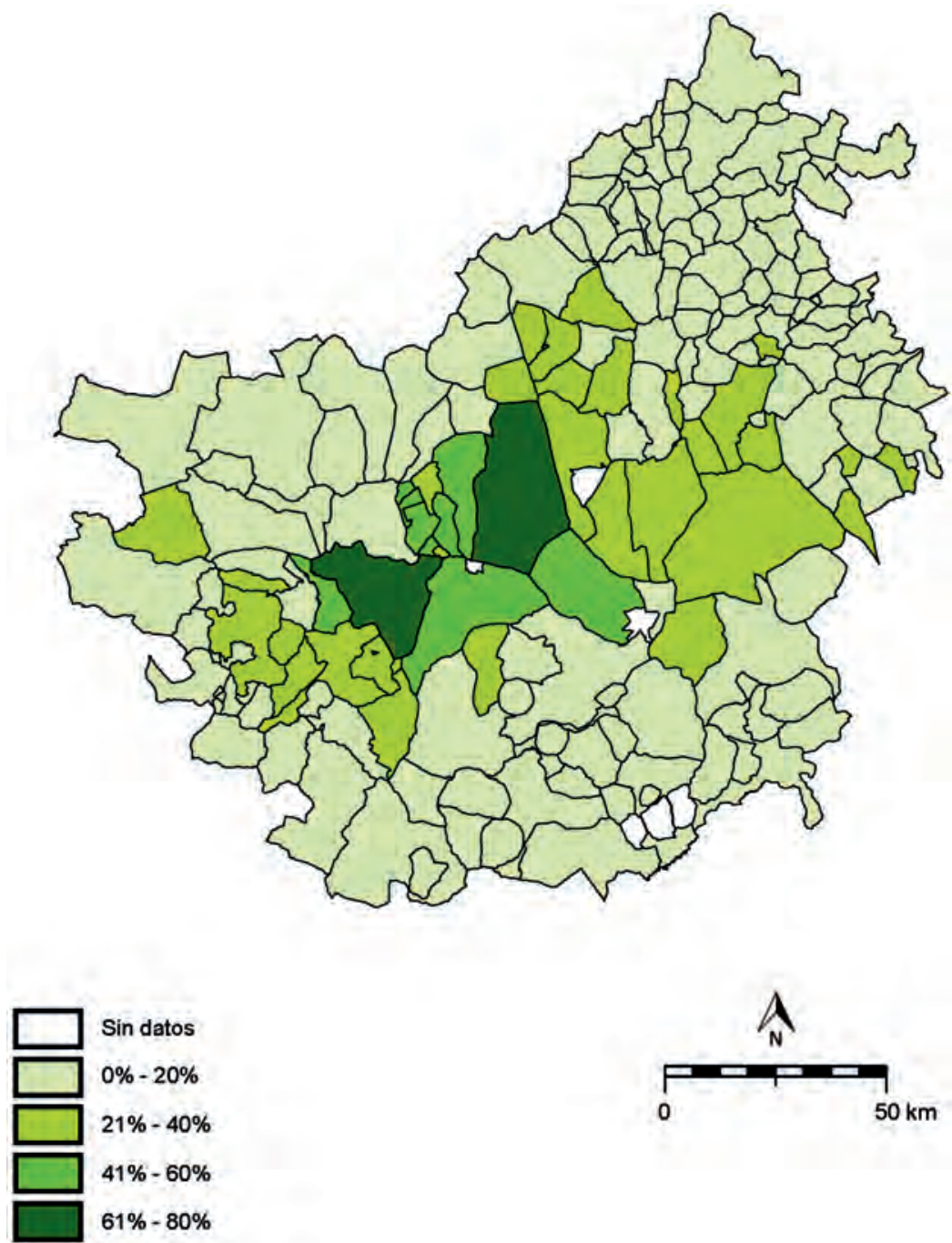

Figura 6. Superficie en regadio respecto al total de tierras de cultivo. Elaboración propia a partir de datos de MARM (2010) y de la CHG (2009b).

Si se compara la Fig. 6 con la de los acuíferos sobreexplotados (Fig. 2) se aprecia una relación directa entre esta sobreexplotación y los municipios con mayor superficie ocupada por tierras en regadío.

Los cultivos herbáceos comprenden un gran número de cultivos anuales de primera importancia, como son el trigo, la cebada, el maíz, el centeno, la colza, el girasol, el algodón y los guisantes, dependiendo su importancia anual de las subvenciones de la PAC. En la zona de estudio, los cereales de grano son los que mayor importancia tienen 
en cuanto a superficie ocupada. Además, debe señalarse la creciente importancia de cultivos hortícolas como tomate, pimiento, melón y berenjena. La alfalfa también muestra una relativamente reciente expansión ligada al sector ganadero (Romero Calcerrada y Martínez Vega, 1997). Respecto a los cultivos leñosos, la totalidad de la superficie es ocupada por olivos, vides y frutales, siendo la vid el cultivo leñoso predominante.

En las Figs. 7, 8 y 9 se analiza la distribución por provincias (sólo en el territorio que abarca el área de estudio) de cultivos herbáceos y leñosos, identificando las hectáreas de regadío y de secano de cada uno, a partir de los datos de las Hojas 1T (MARM, 2009).

\begin{tabular}{lrrrrr}
\hline NOMBRE & SUP. HERBACEOS (ha) & \multicolumn{3}{c}{ SUP. LENOSOS (ha) } & TOTAL \\
\hline TOLEDO & 65.661 & $9 \%$ & 106.256 & $22 \%$ & 239.266 \\
CIUDAD REAL & 284.178 & $40 \%$ & 288.112 & $59 \%$ & 572.290 \\
CUENCA & 286.992 & $40 \%$ & 67.349 & $14 \%$ & 354.341 \\
ALBACETE & 78.230 & $5 \%$ & 29.016 & $6 \%$ & 107.246 \\
\hline TOTAL & 715.061 & $100 \%$ & 490.733 & $100 \%$ & 1.273 .143 \\
\hline
\end{tabular}

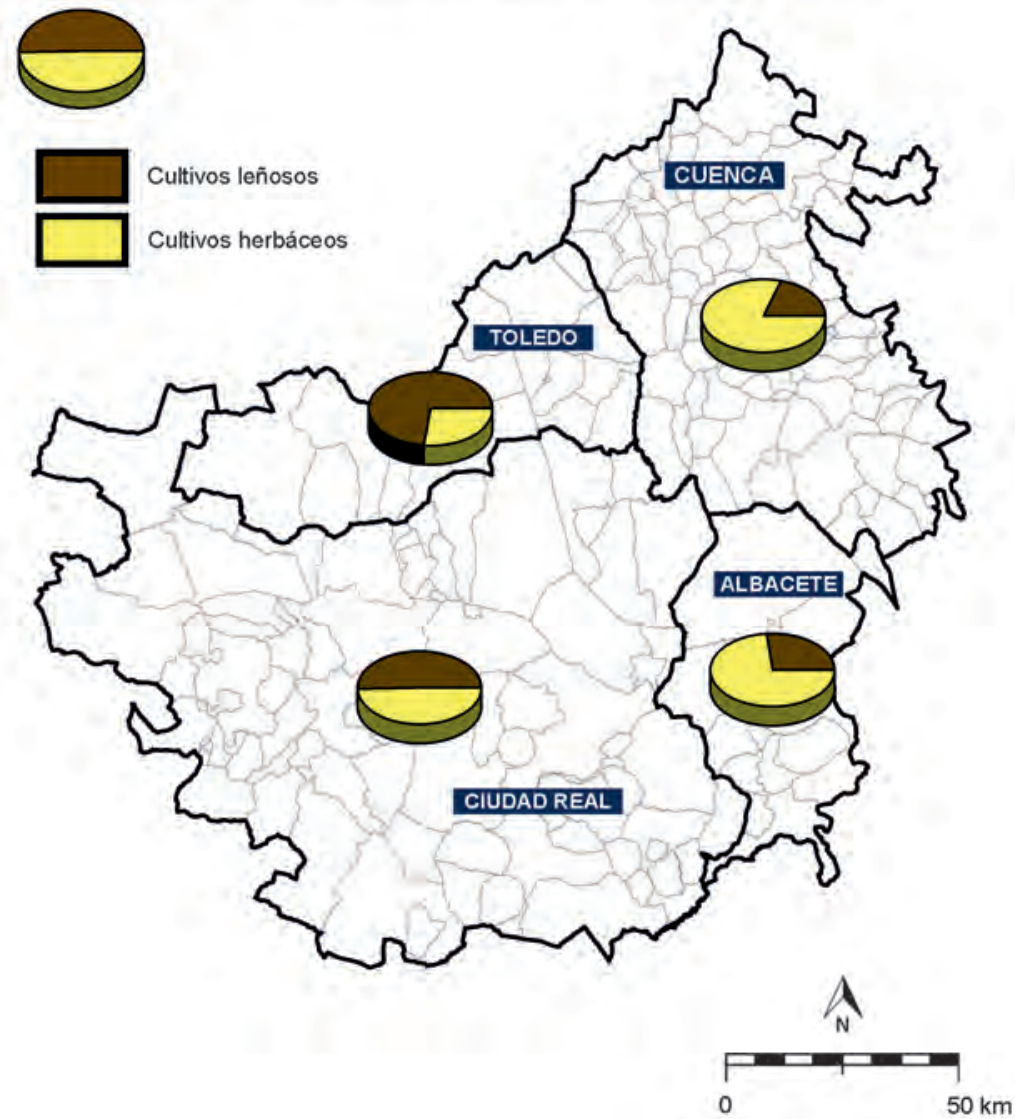

Figura 7. Distribución por provincias, de cultivos herbáceos y leñosos.

Elaboración propia a partir de datos de MARM (2010) y de la CHG (2009b). 


\begin{tabular}{lrrr}
\hline Provincia & Secano (ha) & Regadio (ha) & Herbáceos (ha) \\
\hline TOLEDO & 59.528 & 6.133 & 65.661 \\
CIUDAD REAL & 184.976 & 99.202 & 284.178 \\
CUENCA & 268.579 & 18.413 & 286.992 \\
ALBACETE & 63.935 & 14.295 & 78.230 \\
\hline Total & 577.018 & 138.043 & 715.061 \\
\hline
\end{tabular}

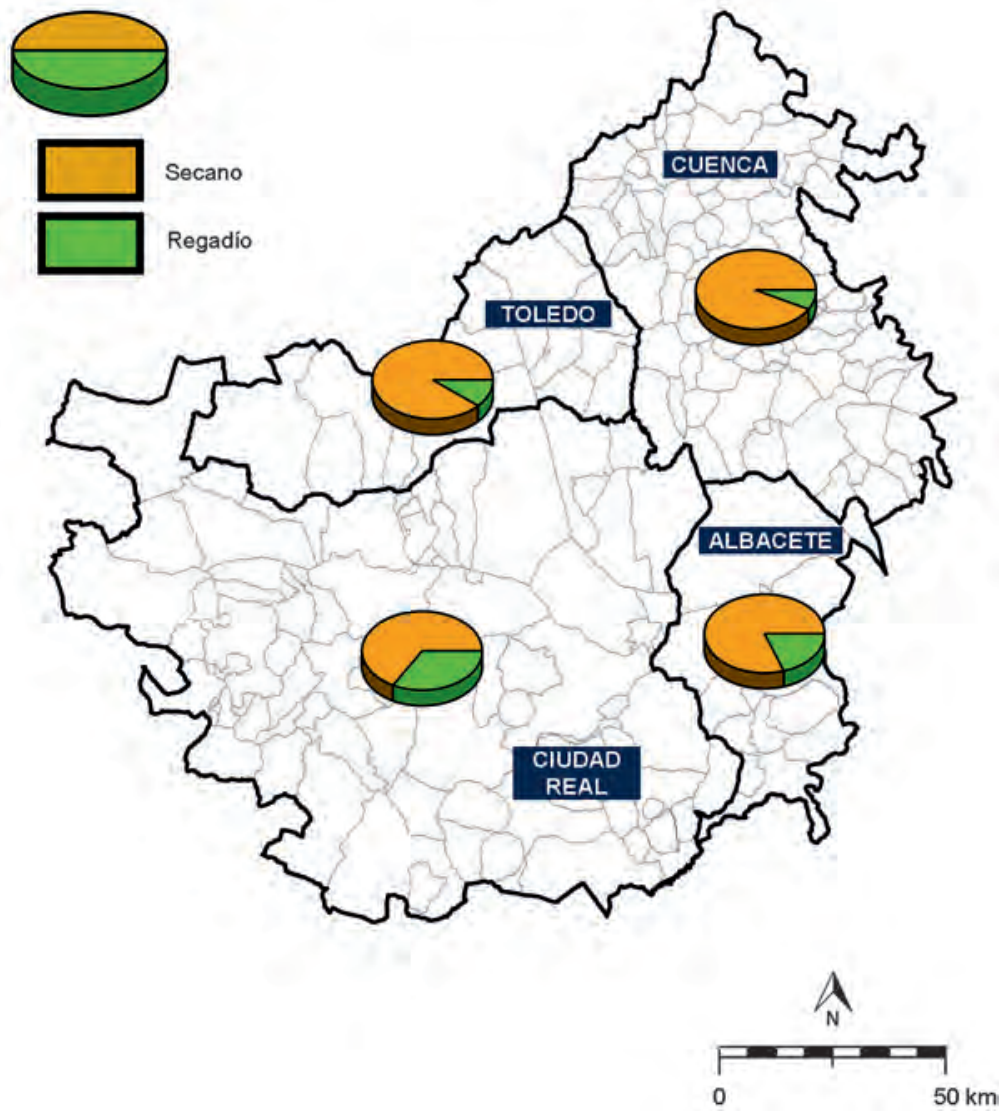

Figura 8. Cultivos herbaceos. Secano y regadío. Elaboración propia a partir de datos de MARM (2010) y de la CHG (2009b).

El secano del Alto Guadiana es fundamentalmente cerealista, con el $36 \%$ de su superficie. Entre los cultivos leñosos de secano destaca el viñedo. De hecho, este cultivo tiende a transformarse a regadío, situación que lo ha convertido en el cultivo predominante de la zona con el $45 \%$ de la superficie (datos del año 2001) (CHG, 2008).

\section{Métodos}

Para la realización de este estudio se han tomado los pagos de la PAC de 2009 en los 169 municipios pertenecientes a la cuenca alta del Guadiana, según la Memoria Téc- 


\begin{tabular}{lrrr}
\hline Provincia & Secano (ha) & Regadio (ha) & Lenosos (ha) \\
\hline TOLEDO & 81.644 & 24.612 & 106.256 \\
CIUDAD REAL & 230.256 & 57.856 & 288.112 \\
CUENCA & 57.570 & 9.779 & 67.349 \\
ALBACETE & 15.671 & 13.345 & 29.016 \\
\hline Total & 385.141 & 105.592 & 106.256 \\
\hline
\end{tabular}

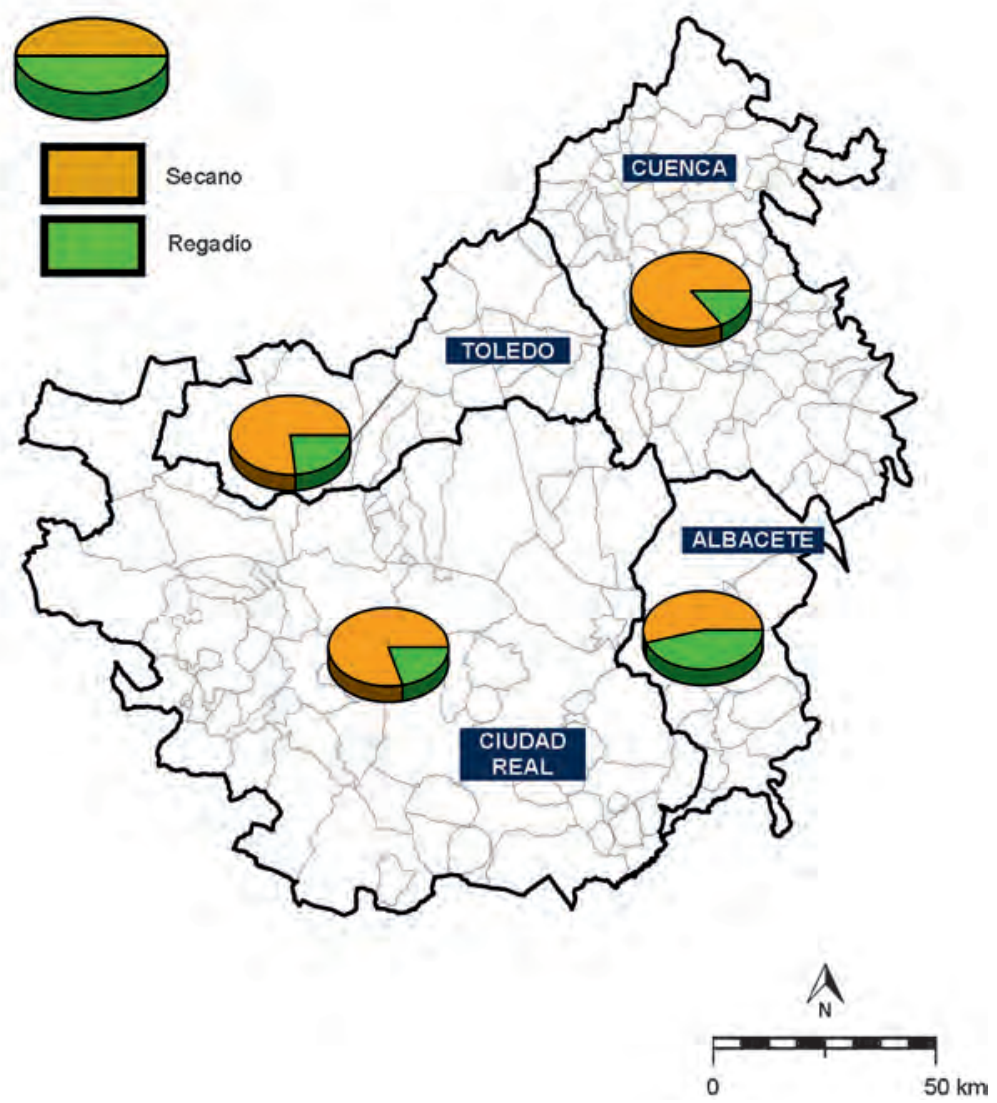

Figura 9. Cultivos leñosos. Secano y regadío. Elaboración propia a partir de datos de MARM (2010) y de la CHG (2009b).

nica del Plan Especial del Alto Guadiana (CHG, 2008). Estos pagos son publicados anualmente en la página web de la Junta de Castilla-La Mancha. Igualmente se ha tomado la superficie agraria útil del mismo año, publicada en el año 2010 (MARM, 2010) en hojas de cálculo, lo que supone un formato más amable para su tratamiento digital, así como la superficie dedicada a cada tipo de cultivo. Los pagos de 2010 se han utilizado para hacer las comparaciones FEAGA-FEADER en este año.

Los pagos se han divido en los pilares correspondientes (FEAGA y FEADER). Igualmente dentro del Pilar I (FEAGA), se distingue entre (i) el Pago Único, que es un subsi- 
dio consistente en el promedio de los apoyos recibidos en los tres años anteriores a 2003 que los perceptores seguirán cobrando los años siguientes independientemente de la producción de las explotaciones (FEAGA, 2010); y (ii) Pagos Sectoriales, parte de ellos aún dependientes de la producción y dirigidos a cultivos herbáceos, leñosos (vid, olivo y frutales), agricultura ecológica, regadío y a la Compensación de Renta de Acuíferos. Esta última tiene el objetivo de reducir el consumo de agua destinada a regadío. La compensación de renta está en función del ahorro al que se acoja cada propietario (López Sanz, 1996).

Las ayudas de los distintos ejes correspondientes al Pilar II (FEADER) han sido consideradas como un único grupo. Debe señalarse, no obstante, que predominan las ayudas del eje1 (Competitividad), del eje 2 (Medio Ambiente) y, en menor medida, del eje 4 (LEADER) mientras que las ayudas correspondientes al eje 3 (Diversificación y calidad de vida en el medio rural) han sido inexistentes.

Una vez obtenidos los datos de las distintas ayudas para los municipios de la zona de estudio, estos valores han sido divididos por las hectáreas de superficie agraria útil en cada uno de ellos, o bien entre la superficie dedicada al cultivo al que va destinada la ayuda correspondiente, buscando una relación directa entre una mayor producción, o uso del regadío, y mayores ayudas de la PAC. Dicha valoración se ha llevado a cabo mediante el cruce y comparación de los mapas obtenidos con el programa ArcGis a partir de los datos del Ministerio de Medio Ambiente, Rural y Marino de 2009, de las capas GIS proporcionadas por la Confederación Hidrográfica del Guadiana y de los pagos de la PAC en la zona de estudio.

Debe tenerse en cuenta el sesgo en la interpretación estadística debido a que los pagos de las ayudas de la PAC están referidos al domicilio del beneficiario y no a la ubicación de las explotaciones que generan dichas ayudas. Así, algunos importes podrían derivar de explotaciones situadas fuera del término municipal en cuestión, o que no se hayan considerado pagos asociados a explotaciones situadas en la zona de estudio cuyos beneficiarios residen en otros municipios. No obstante, se puede asumir que la magnitud de estas distorsiones no es tan grande como para invalidar los análisis realizados o las conclusiones alcanzadas.

Asimismo, de tres de los municipios (Ruidera, Arenales de San Gregorio y Llanos del Caudillo) incluidos en el PEAG no han podido encontrarse datos de superficie agraria útil ni de la dedicada a los distintos cultivos, por lo que no han podido ser tenidos en cuenta en el estudio. Otros tres municipios que aparecen en blanco en los mapas son Puebla del Príncipe, Trinches y Albadalejo. Estos municipios no han sido tenidos en cuenta en el PEAG por lo que tampoco se han considerado en este estudio.

\section{Resultados}

\subsection{Distribución general de las ayudas}

La Fig. 10 muestra la distribución total de las ayudas, tanto del Pilar I (FEAGA) como del Pilar II (FEADER). Se observa que los pagos del FEAGA superan con creces a los derivados del FEADER. En estos últimos, el eje 1 (Competitividad) y el eje 2 


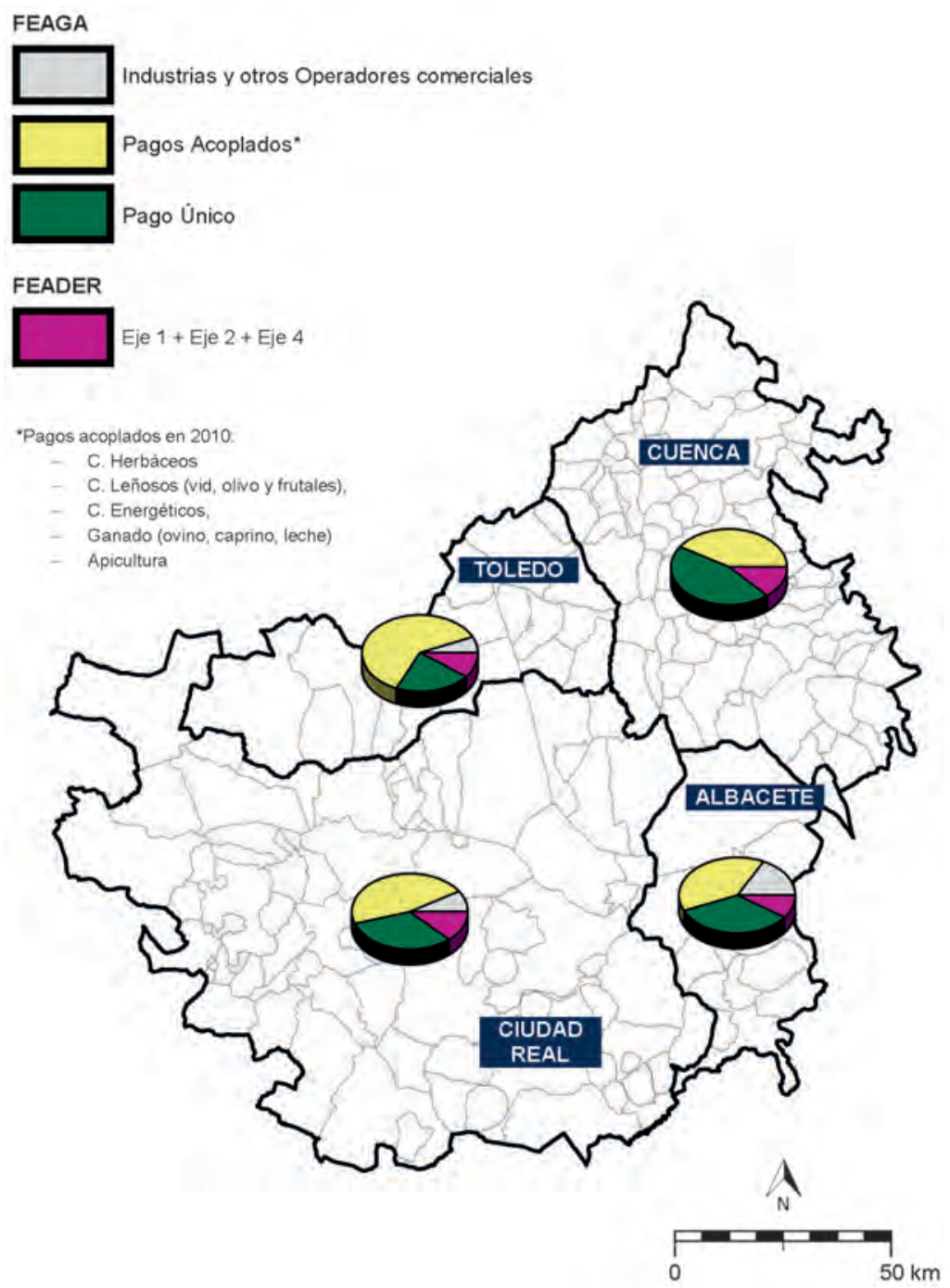

Figura 10. Distribución de los pagos de FEAGA y FEADER en 2010.

Elaboración propia a partir de datos de FEAGA (2011).

(Medio Ambiente y Desarrollo Rural), suponen casi el 100\% de las ayudas del FEADER, distribuyéndose en una proporción similar (45\% y $47 \%$ respectivamente) y por ello no se analizan por separado.

Dentro de las ayudas procedentes del FEAGA (pago único, pagos acoplados y ayudas a industrias y otros operadores comerciales), los pagos acoplados a la producción representan un porcentaje mucho mayor de lo que cabría esperar teniendo en cuenta que desde 2003 la PAC se ha orientado hacia el desacoplamiento de las ayudas respecto de 
la producción. De hecho, en España los pagos acoplados representan tan solo un 15\% de los pagos FEAGA. La presencia de un porcentaje significativo de ayudas acopladas en el Alto Guadiana parece indicar que la PAC sigue siendo un fuerte incentivo para explotaciones intensivas y de regadío, con mayores tasas de producción. Estos pagos son analizados de forma íntegra y desglosada en los apartados siguientes.

\subsection{FEAGA - Pagos acoplados y pago único}

A continuación se analizan los pagos del Pilar I de la PAC para el año 2009, examinando las ayudas acopladas a la producción en los distintos sectores y el pago único (Fig. 11). Las ayudas destinadas a la ganadería no se tienen en cuenta por no relacionarse directamente con la sobreexplotación de acuíferos.

De las ayudas consideradas, las destinadas a la Agricultura Ecológica y la Compensación de Renta de Acuíferos son insignificantes en relación con las ayudas restantes. Esto sugiere dos consideraciones en relación con el estado de los recursos hídricos en el Alto Guadiana:

(a) La agricultura ecológica, que puede contribuir a reducir la contaminación de las aguas y del suelo, actualmente no se ve impulsada de forma significativa por las ayudas de la PAC.

(b) El plan de compensación de rentas, iniciado en el año 1993 y que consiste en ayudas a los agricultores que deciden dejar de regar parte de sus tierras, tiene un nivel de acogida bajo entre los agricultores (Martínez Santos et al., 2008) y por tanto un impacto limitado sobre la recuperación de los niveles piezométricos en la zona.

El peso de las ayudas al regadío es escaso, en concordancia con los nuevos objetivos de la PAC de protección medioambiental. No obstante, los pagos acoplados representan algo más de la mitad de las ayudas de la PAC en la zona de estudio lo que implica una ayuda indirecta al regadío por ser el método con el que se consiguen las mayores producciones.

\subsubsection{Ayudas a cultivos leñosos}

Entre los cultivos leñosos existe un claro predominio de la vid respecto a frutales y olivares, siendo el sector vitivinícola el más beneficiado por las ayudas del FEAGA.

Tradicionalmente, los viñedos han sido cultivados en secano con extensas concentraciones monoculturales en el extremo sudoriental de la provincia de Toledo y en el nororiental de la de Ciudad Real, donde algunos municipios dedican más del $70 \%$ de la superficie al viñedo, entre lo que destacan Pedro Muñoz, Miguel Esteban y la Puebla de Almoradiel (Peinado et al., 2009). Sin embargo, desde 1993 se ha producido un constante incremento de la superficie de viñedo en regadío que en esa fecha sólo ocupaba 9680 ha. En el año 2007, el viñedo en secano representaba en la zona de estudio el 76.9\% de superficie total de viñedo, mientras que el viñedo en regadío había pasado a representar el $23 \%$ 


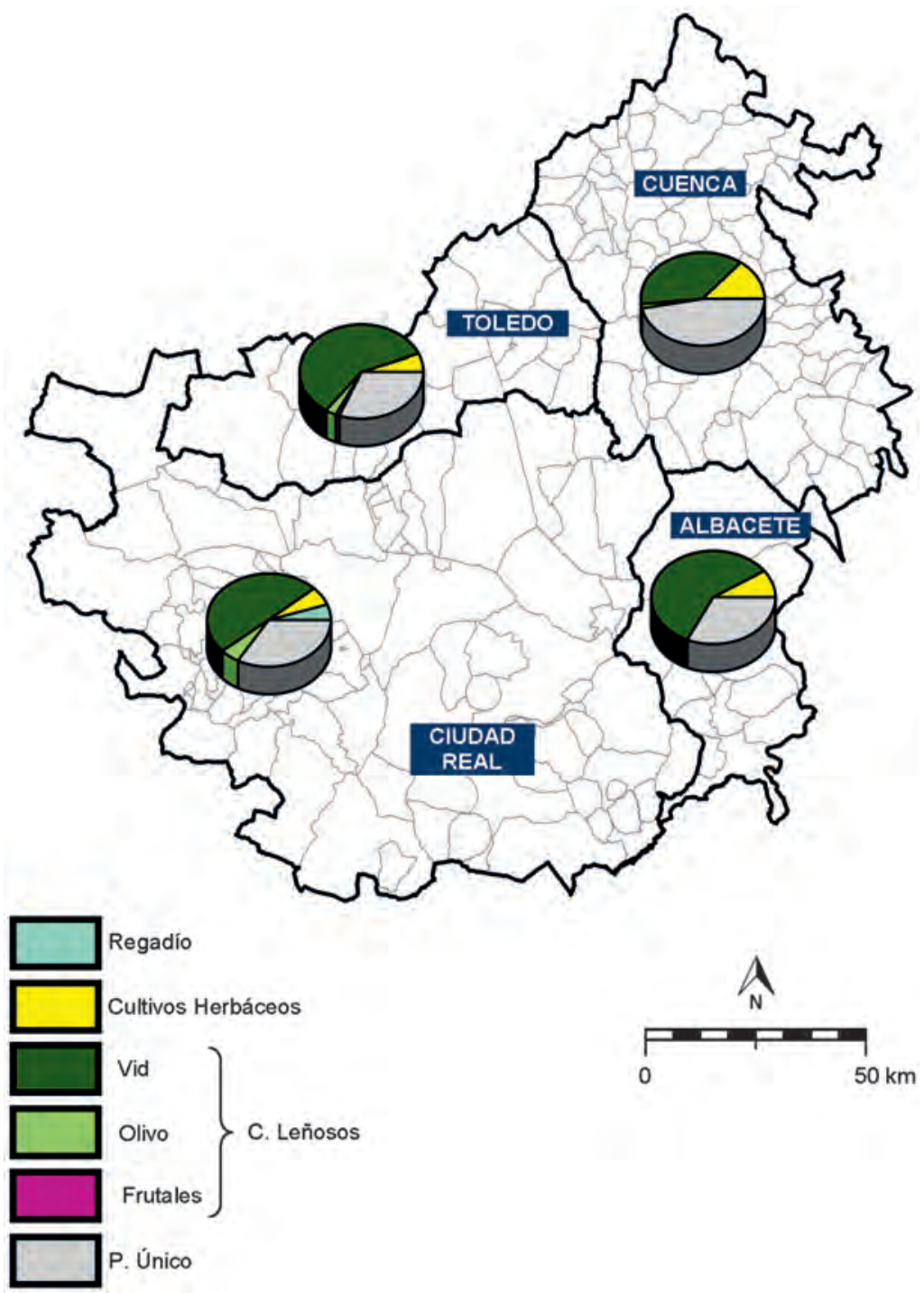

Figura 11. La proporcionalidad entre los pagos del FEAGA. Elaboración propia a partir de datos de JCCM (2009).

del total. Para explicar esta evolución debe tenerse en cuenta que desde 1996 se levantaron las limitaciones al cultivo del viñedo en regadío, que curiosamente no existían en el resto Europa. Por otro lado, según Peinado et al. (2009), desde 1999 los agricultores manchegos procedieron a introducir variedades de vid con mayores necesidades de agua, cultivadas en modalidades (espaldera) que ofrecen pocas perspectivas sin riego de apoyo. Se pasó, por lo tanto, de un viñedo bien adaptado a las bajas precipitaciones del Alto Guadiana a otro cada vez más dependiente de los aportes de riego. Este hecho ha implicado 
una presión creciente sobre los recursos hídricos en la zona. Si se tiene en cuenta que una hectárea de viñedo necesita un riego de aproximadamente $1500 \mathrm{~m}^{3}$ por año, puede estimarse que las 105600 ha de viñedo en regadío registradas en 2009 consumen un total de casi $158 \mathrm{hm}^{3}$, cuando la máxima extracción anual que se considera sostenible para el acuífero está alrededor de $250 \mathrm{hm}^{3}$ (CHG, 2008). No obstante, el consumo de agua en viñedo puede llegar a limitarse a $500 \mathrm{~m}^{3}$ en riego por goteo.

En la tabla 2 se informa sobre la proporción de ayudas entre los distintos cultivos leñosos de la zona agrupando los municipios del Alto Guadiana en sus respectivas provincias para tener una idea general del área de estudio.

Tabla 2. Pagos de la PAC destinados a cultivos leñosos (\%). Año 2009.

\begin{tabular}{|l|c|c|c|c|c|}
\hline & Albacete & Ciudad Real & Cuenca & Toledo & Total regional \\
\hline Sector vitivinícola & $97.64 \%$ & $90.10 \%$ & $96.19 \%$ & $93.31 \%$ & $180909648 €$ \\
\hline Olivar & $1.32 \%$ & $9.40 \%$ & $3.00 \%$ & $4.71 \%$ & $13615549 €$ \\
\hline Frutales & $1.03 \%$ & $0.5 \%$ & $0.80 \%$ & $1.98 \%$ & $1615210 €$ \\
\hline
\end{tabular}

Fuente: Elaboración propia a partir de datos de la Junta de Comunidades de Castilla-La Mancha (JCCM).

Las ayudas a viñedos (sector vitivinícola) superan en toda la cuenca alta del Guadiana el $90 \%$ de los pagos destinados a cultivos leñosos especialmente en el sector correspondiente a las provincias de Albacete y Cuenca. Esto sugiere, de entrada, que la vuelta al cultivo en secano de la vid será fundamental en la futura recuperación de los recursos hídricos. De hecho, ante la excesiva superficie dedicada al viñedo y la necesidad de fomentar más la calidad, la PAC prohibió nuevas plantaciones e incentivó el arranque de las menos productivas. La respuesta por parte de los agricultores no fue arrancar las cepas sino cambiar las marcos de plantación hacia emparrado o espaldera, con aumento del número de cepas por hectárea y facilitando el riego por goteo (Martínez Vega et al., 1995).

Las Figs. 12 y 13 reflejan, por un lado, las ayudas en $€ /$ ha a cultivos leñosos adjudicadas a cada municipio, y por otro lado, el porcentaje de cultivos leñosos en regadío de cada municipio. Los resultados obtenidos en el caso de los cultivos leñosos no reflejan, de forma clara, una relación directa entre las ayudas por hectárea procedentes del FEAGA y los municipios con mayor proporción de cultivos leñosos en regadío.

No obstante, por la importancia de estos cultivos, especialmente de la vid, se comparan también las Figs. 12 y 13 con la Fig. 14 (Ayudas al regadío en el Alto Guadiana), con el fin de conocer si el paso de viñedos de secano a regadío está siendo potenciado por la PAC. Si esto es así se confirmaría que las explotaciones más productivas siguen siendo las que más ayudas reciben. Efectivamente, en esta comparación se aprecian en la mayor parte de los términos municipales alguna o varias de las siguientes relaciones directas: 
Figura 12. Ayudas del FEAGA a Cultivos leñosos con independencia de que estén en secano o regadio. Elaboración propia a partir de datos de JCCM (2009) y de la CHG (2009b).
Figura 13. Cultivos leñosos en regadio. Elaboración propia a partir de datos de JCCM (2009) y de la CHG (2009b).
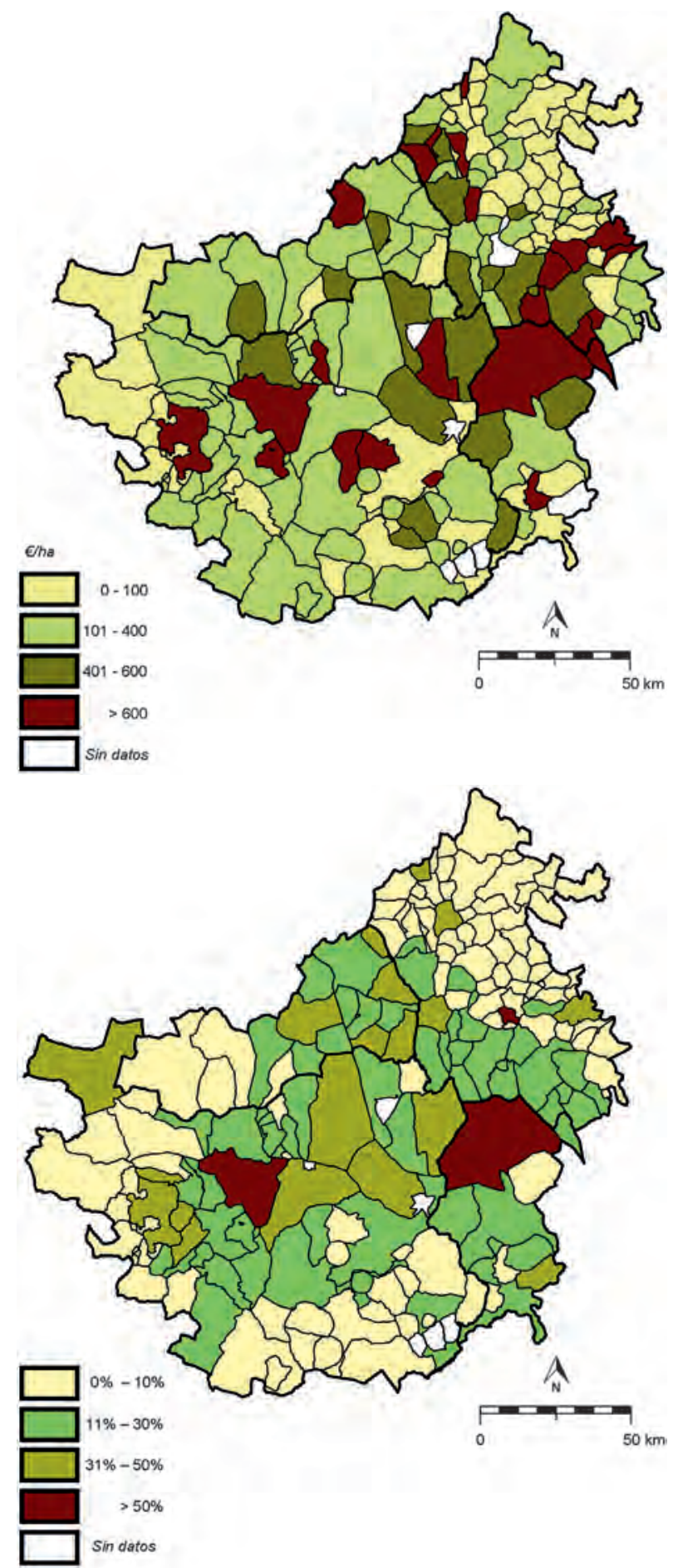


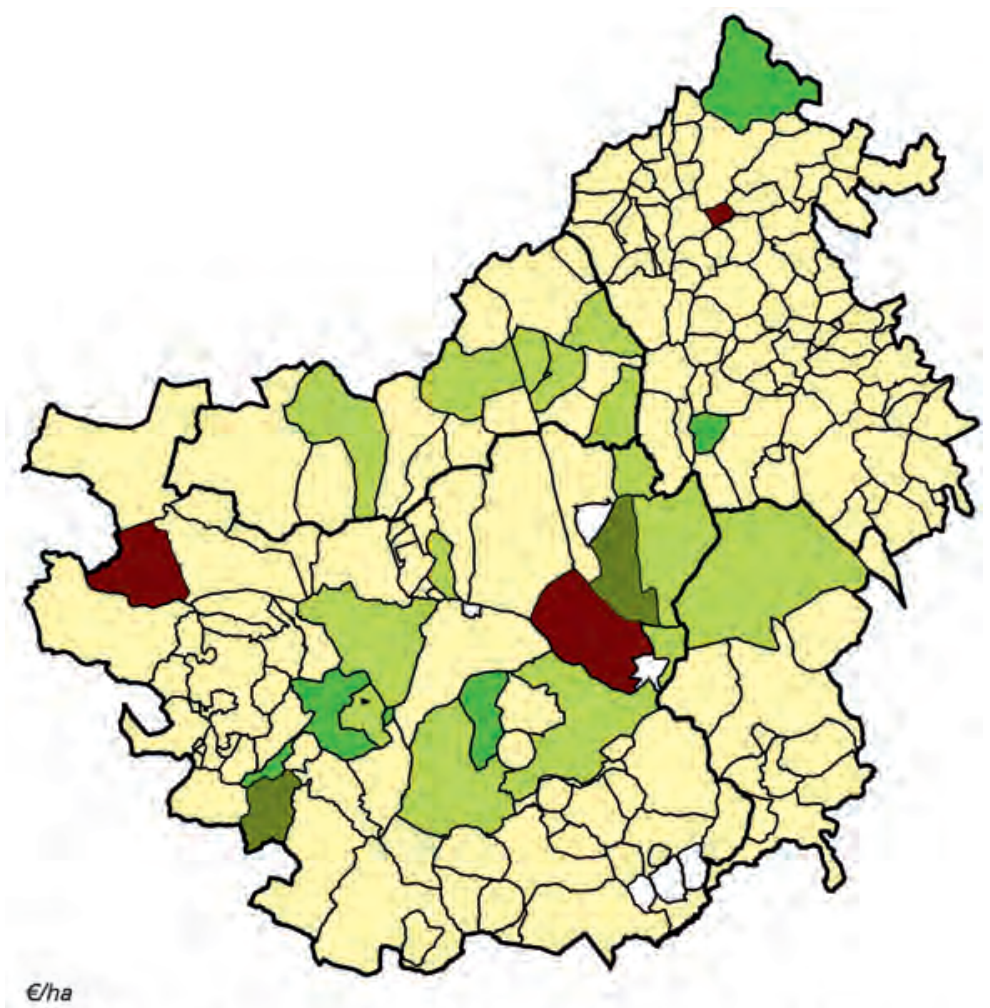

G/ha

Términos municipales que no reciben ayudas al regadio

$1-10$

$11-30$

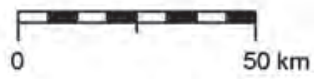

$31-100$

$>100$

Sin datos

Figura 14. Ayudas del FEAGA al regadío en el Alto Guadiana. Elaboración propia a partir de datos de JCCM (2009)

$y$ de la CHG (2009b).

(i) Ayudas del FEAGA a cultivos leñosos y la proporción de hectáreas en regadío.

(ii) Ayudas del FEAGA a cultivos leñosos y ayudas al regadío.

(iii) La proporción de hectáreas en regadío y las ayudas al regadío.

Aunque hay municipios en los que no se da ninguna de estas relaciones, es conveniente recordar que los pagos quedan registrados en el municipio de residencia del receptor por lo que los municipios menos poblados contarán, generalmente, con menos ayudas. Asimismo, no se reflejan las ayudas a perceptores cuyos domicilios queden fuera de los límites de la zona de estudio. No obstante, la validez de este estudio reside en la hipótesis de que el receptor de estos pagos, si bien puede que no resida en el mismo municipio donde 

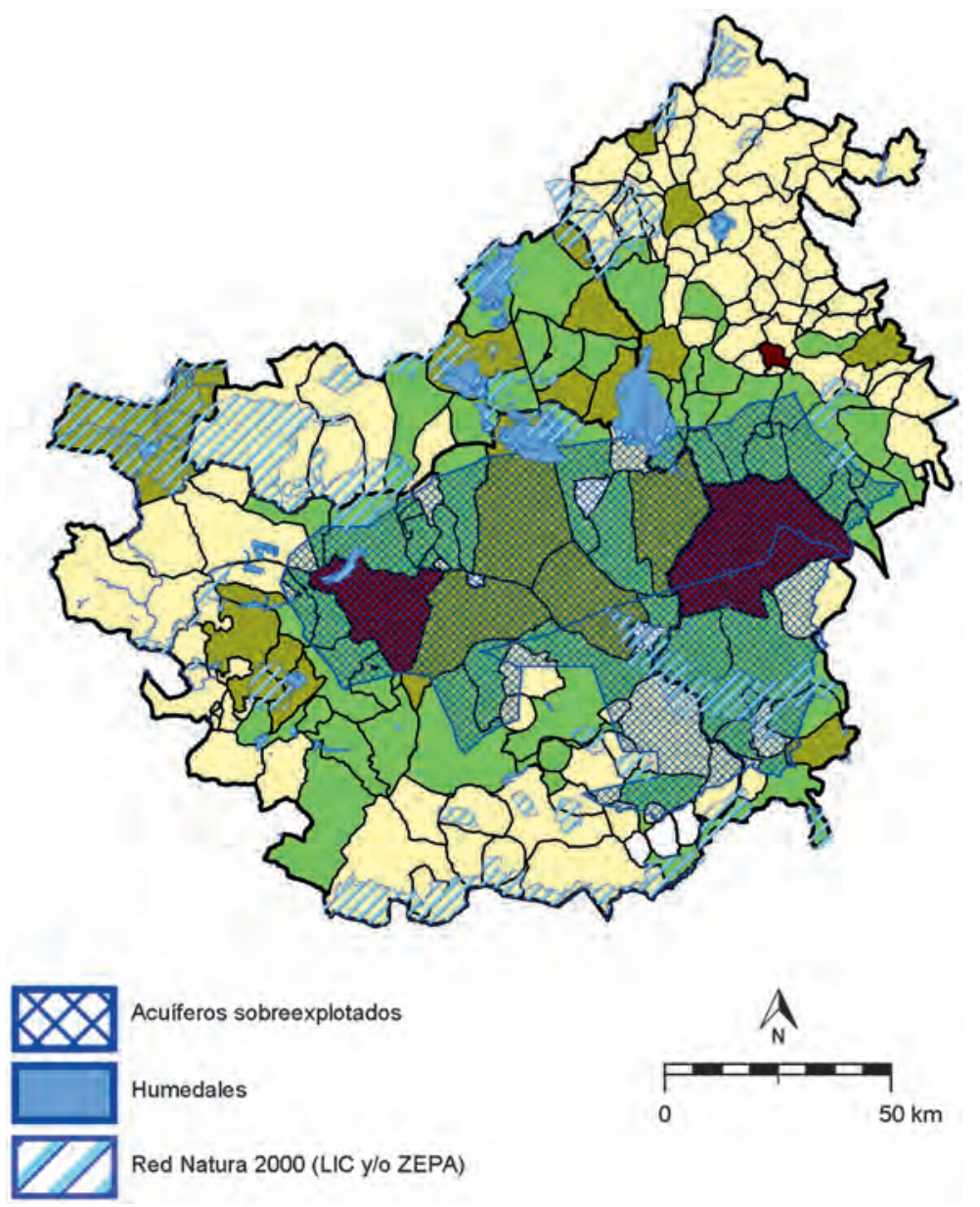

Acuiferos sobreexplotados

Humedales

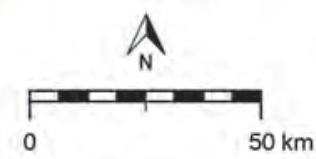

Figuras 15. Superposición del porcentaje de cultivos leñosos en regadío (Figura 13), espacios naturales protegidos y acuíferos sobreexplotados. Elaboración propia a partir de datos de JCCM (2009) y de la CHG (2009b).

se encuentran los campos por los que recibe la ayuda, su domicilio no se situará excesivamente alejado de ellos, por lo que a nivel de zonas, como aquellas donde existen acuíferos sobreexplotados o aquellas de mayor valor ambiental, estas relaciones se cumplen. La limitación expuesta se magnifica en municipios como Belmonte en Cuenca y Robledo en Albacete, donde las ayudas del FEAGA a cultivos leñosos superan los $20000 € /$ ha. Evidentemente estos resultados no son representativos de los pagos reales correspondientes a las explotaciones de estos situadas en dichos términos municipales.

En lo referente a la explotación de los recursos hídricos, en la Fig. 15 se relacionan éstos con la proporción de cultivos leñosos en regadío en los distintos municipios. Se observa que los municipios con mayor proporción de hectáreas de cultivos leñosos en 
regadío coinciden casi en su totalidad, con zonas LIC y/o ZEPA (Red Natura 2000), con UU.HH sobreexplotadas y/o con humedales de gran valor medioambiental (Fig. 15).

\subsubsection{Ayudas a Cultivos Herbáceos y comparación con el Pago Único}

No se percibe una relación directa entre los municipios con mayores hectáreas dedicadas a cultivos herbáceos en regadío y los municipios que reciben mayores ayudas del FEAGA destinadas a este sector. Por tanto, los pagos a cultivos herbáceos no están directamente asociados con la productividad de las explotaciones.

En principio parece que es en este sector donde queda potenciado el Pago Único respecto a los pagos acoplados. Así al comparar los mapas resultantes de ambos pagos se aprecia una clara analogía entre las ayudas recibidas por hectárea de cultivo gracias al Pago Único y los pagos ligados directamente a la producción de cultivos herbáceos por hectárea cultivada. Al establecerse el Pago Único como una media de las ayudas recibidas en los tres años de referencia, cabría esperar en él valores mucho mayores, si realmente una parte significativa de las ayudas destinadas a cultivos leñosos durante esos años hubieran pasado a formar parte del Pago Único. No obstante, los pagos desacoplados a la producción (Pago Único) son significativamente coincidentes, tanto en valor como en localización con las ayudas a cultivos herbáceos, siendo mayores en los municipios donde las ayudas a este tipo de cultivos también lo son y disminuyendo según la misma relación (Figs. 16 y 17).

La única explicación encontrada al fenómeno descrito es que el Pago Único en el año de estudio, 2009, queda conformado mayoritariamente (aunque no únicamente) por el valor medio de las ayudas a la producción de cultivos herbáceos durante los años de referencia.

En su mayoría los pagos relacionados con cultivos leñosos aún quedan ligados a la producción con lo que no forman parte importante de los denominados pagos desacoplados. Es decir, se confirma que las explotaciones más productivas de cultivos leñosos, las explotaciones en regadío, continúan recibiendo más ayudas de la PAC, con la consiguiente presión, cada vez mayor, sobre los acuíferos de la zona. Igualmente, este hecho explica el cambio incesante de viñedos de vaso (secano) a espaldera (regadío), paisaje cada vez más común en la cuenca alta del Guadiana.

De esta forma, aunque las ayudas a regadío no sean significativas en la zona de estudio, la explotación intensiva de los acuíferos sigue viéndose favorecida por las ayudas de la PAC al estar éstas íntimamente ligadas a la producción, en el caso de los cultivos leñosos. En caso de que la totalidad de las ayudas acopladas a la producción desaparecieran, es posible que muchas explotaciones en regadío dejasen de ser rentables, disminuyendo por tanto la presión sobre los acuíferos.

\section{Discusión y conclusiones}

El Alto Guadiana presenta una elevada importancia ambiental debido a la presencia de numerosos humedales con una gran biodiversidad, destacando entre ellos el Parque Nacional de las Tablas de Daimiel y las Lagunas de Ruidera. Esta importancia 


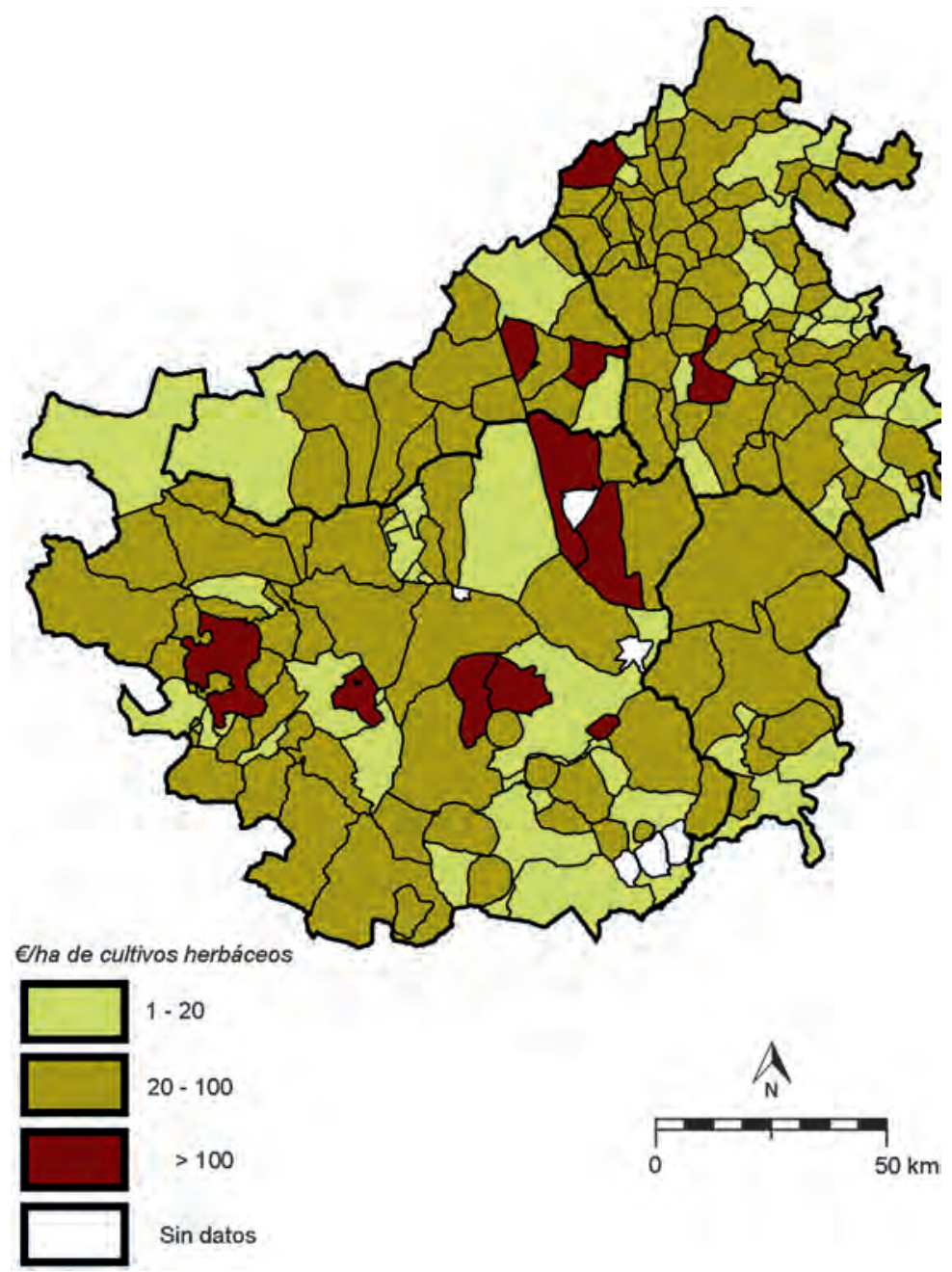

Figura 16. Ayudas del FEAGA a cultivos herbáceos. Elaboración propia a partir de datos de JCCM (2009) y de la CHG (2009b).

ambiental debe hacer frente, sin embargo, a la fuerte presión existente en las últimas décadas sobre los recursos hídricos subterráneos. La utilización de tales recursos para la expansión de cultivos de regadío ha provocado un marcado descenso de los acuíferos por sobreexplotación (y de la riqueza de especies relacionadas con los humedales), reduciéndose la extensión de áreas inundadas, en parte debido a la PAC (López González, 2002, Pillet Capdepón, 2011). Así, el Parque Nacional ha visto limitada su superficie inundada a una séptima parte de la existente hasta la década de 1960 .

La utilización de los recursos hídricos subterráneos ha permitido extender la superficie de regadío hasta 262868 ha en 2001, favoreciendo la producción de maíz, remola- 


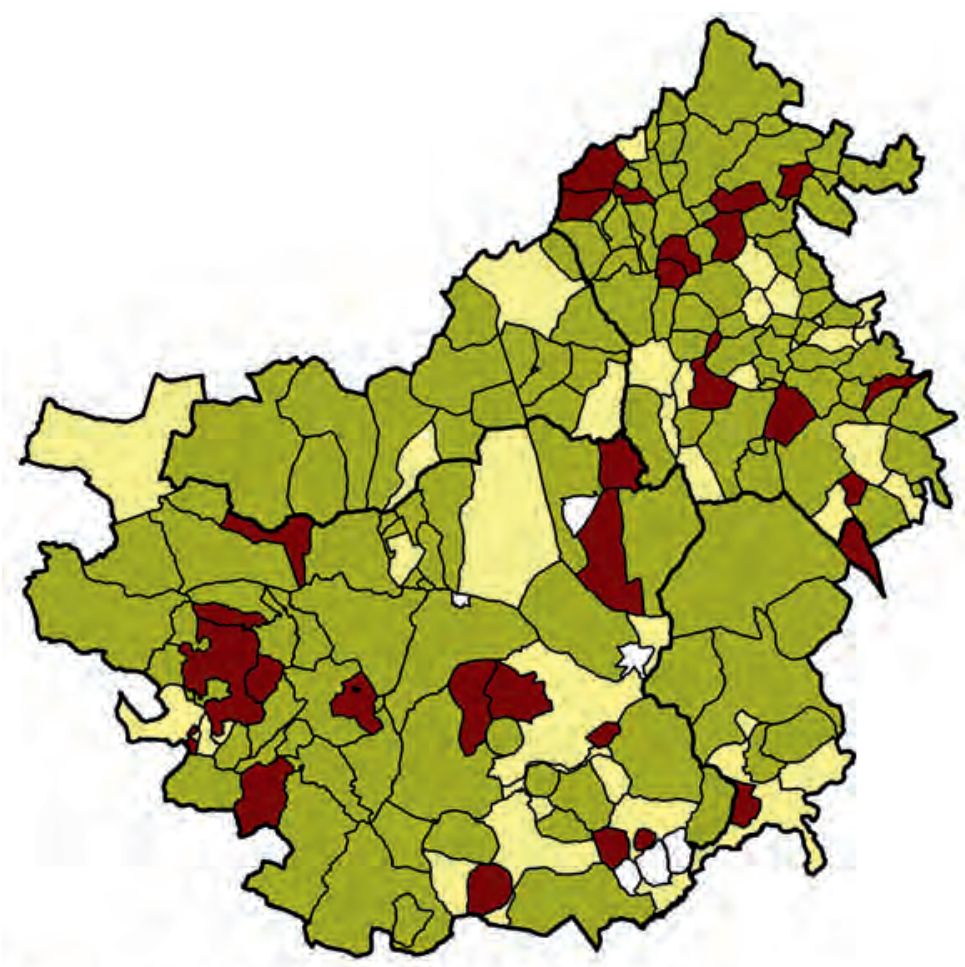

Eha de tierras de cultivo

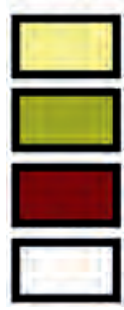

$1-40$

$40-120$

$>120$

Sin datos

Figura 17. Distribución del Pago Único. Elaboración propia a partir de datos de JCCM (2009) y de la CHG (2009b).

cha azucarera, alfalfa, ajo, melón y viñedo, este último cada vez más incorporado al regadío mientras las vides en secano están en retroceso. No obstante, la sobreexplotación de los acuíferos se hizo insostenible en la década de 1980, lo que obligó a adoptar una serie de medidas destinadas a la recuperación de la recarga subterránea frente a la idea, casi general entre los agricultores, de que los recursos de agua eran inagotables (Martínez Vega et al., 1995). Según estos autores, a ello ha contribuido también la inexistencia de tradicionales comunidades de regantes, que hubieran podido reglamentar el uso del agua de forma racional. La Administración también ha sido responsable en la medida en que ha facilitado créditos blandos para la transformación en regadío. En la 
actualidad, el regadío consume el $90 \%$ del agua subterránea extraída y la tendencia no disminuye dada la creciente importancia de cultivos altamente consumidores (Holtz y Pahl-Wostl, 2012). El Plan de Regeneración Hidrológica incluye la construcción de dos presas para retener el agua en el Parque Nacional de las Tablas de Daimiel y el trasvase de agua desde el alto Tajo a través del trasvase Tajo-Segura. Todo ello ha sido insuficiente por las ayudas comunitarias a la producción, que inducen al regadío y a la extracción de agua mediante pozos, muchos de ellos ilegales.

Diferentes autores han hecho propuestas razonables para mejorar el nivel de los acuíferos. Así, Conan et al. (2003), aplicando el modelo SWAT, concluyen en la necesidad de sustituir los cultivos con alto consumo de agua (remolacha, alfalfa y maíz) por otros con menos requerimientos hídricos (viñedos o girasol), lo que reduciría el volumen de riego y elevaría el nivel piezométrico. Fornés et al. (2000) añaden además la necesidad de extender el riego por goteo de forma generalizada. López Sanz (1999) propone reducir los bombeos a $150 \mathrm{hm}^{3}$ por año, es decir, unos $100 \mathrm{hm}^{3}$ por debajo de la recarga natural; ese excedente sería capaz de recuperar el acuífero en alrededor de 45 años, y en menos tiempo si se complementase con aportes desde la cuenca del Tajo. Sus propuestas de gestión agrícola también aluden a la necesidad de eliminar el cultivo de alfalfa y remolacha y el regadío en viñedos, manteniendo en cambio los cereales de invierno que se complementan muy bien con las explotaciones extensivas de ganado ovino. Todo ello, claro está, necesitaría una estrategia de financiación desde la PAC muy diferente de la actual. En todo caso, el empleo de modelos para la gestión de territorios con predominio de usos agrario es imprescindible para mejorar la toma de decisiones y un mejor aprovechamiento de los recursos hídricos (Giménez et al., 2012).

Los problemas a los que se enfrenta la recuperación de los acuíferos y la explotación agrícola del territorio a medio y largo plazo, se agravan cuando se analizan los escenarios climáticos futuros previstos para la región. Kilsby et al. (2007) apuntan hacia una marcada reducción de las precipitaciones, que estaría en torno a un 26\%, especialmente durante la estación húmeda (noviembre a mayo). Estos autores indican además que los tratados entre España y Portugal y el abastecimiento de agua a las áreas urbanas y rurales de Portugal, estarán sujetos a crecientes problemas. Xu et al. (2007) estudiaron el cambio climático en las cuencas del Tajo y del Guadiana, comparando la precipitación de octubre y noviembre del periodo 1961-1990 con la prevista en 2070-2099, representando la precipitación futura entre un 0.80 y un 0.85 de la lluvia de referencia. Esos dos meses son muy importantes para la recuperación de los ríos y acuíferos. Todo esto sugiere que es imprescindible adoptar medidas de gestión de los recursos hídricos a través de la política agraria.

Desde un punto de vista agrícola, las conclusiones de este trabajo son las siguientes:

(i) El análisis de los datos relativos a las ayudas de la PAC muestra el escaso peso del FEADER respecto al FEAGA en la zona de estudio. Igualmente se observa el elevado valor de las ayudas acopladas a la producción en comparación con el Pago Único dentro de un análisis individual de las ayudas del FEAGA. Estos resultados parecen contradecir la idea de favorecer otras for- 
mas de desarrollo rural como aquellas basadas en el incremento de la comercialización o de la calidad sin tener que recurrir al aumento de la productividad a través del regadío y el empleo intensivo de fertilizantes.

(ii) Las ayudas asociadas a cultivos herbáceos son las que han pasado a conformar mayoritariamente el Pago Único, mientras que los pagos asociados a cultivos leñosos siguen siendo mayores en las explotaciones con mayor producción (tierras con cultivos en regadío). No obstante, los cultivos herbáceos han sido tradicionalmente de secano en la zona sin que hayan experimentado una gran conversión al regadío a lo largo del tiempo. Por tanto, el Pago Único recoge fundamentalmente cultivos de secano mientras que la PAC continúa favoreciendo indirectamente los cultivos en regadío, al ligar los pagos a la mayor producción de cultivos leñosos (vid, especialmente), que sí presentan fuertes conversiones de secano a regadío. Esta situación conlleva, por tanto, un incentivo de la PAC hacia una presión cada vez mayor sobre los recursos hídricos del Alto Guadiana, incentivando tanto su sobreexplotación como la contaminación por nitratos de origen agrario (utilización del regadío y fertilizantes como medios para alcanzar una mayor productividad).

(iii) En un intento de ser coherentes con las intenciones medioambientales de la PAC las ayudas directas al regadío en esta zona son escasas en comparación con las destinadas a cultivos leñosos o al Pago Único. No obstante, esta coherencia queda rota por el hecho de que las mayores ayudas están destinadas a los cultivos más intensivos, siendo éstos, en la cuenca alta del Guadiana, los cultivos en regadío.

(iv) Se aprecia una relación clara entre los pagos acoplados de la PAC -y en particular la ayuda directa al viñedo- y el estado de los recursos hídricos, coincidiendo, en gran parte de los casos, los mayores niveles de pagos con municipios situados sobre acuíferos sobreexplotados y/o en espacios naturales protegidos. Asimismo, este mayor nivel de ayudas, por lo general, coincide con los municipios con mayor proporción de cultivos leñosos en regadío por hectáreas de tierras de cultivo. Así queda confirmada la gran presión que ejerce el riego de viñas sobre los recursos subterráneos del Alto Guadiana, a pesar de que el viñedo es, entre las opciones de regadío, el cultivo que menos agua consume por hectárea. Sin embargo, la subvención de la PAC a la producción (pago acoplado) favorece la transformación de las viñas de secano a regadío, aumentado así la presión sobre los recursos hídricos subterráneos.

(v) Las ayudas destinadas a la agricultura ecológica y la compensación de renta de acuíferos son insignificantes en relación con las ayudas restantes. Esto sugiere dos reflexiones en relación con el estado de los recursos hídricos en el Alto Guadiana: 1. La agricultura ecológica, que puede contribuir a reducir la contaminación de las aguas y del suelo, no se ve impulsada de forma significativa por las ayudas de la PAC. 2. El plan de compensación de rentas, cuyo inicio tuvo lugar en el año 1993 y que consiste en ayudas a los agricultores que deciden dejar de regar parte de sus tierras, tiene actualmente un 
nivel de acogida bajo entre los agricultores y, por tanto un impacto limitado sobre la recuperación de los niveles piezométricos.

(vi) Dada la situación de menor nivel de ayudas a los sistemas más valiosos desde el punto de vista ambiental (explotaciones en secano y agricultura ecológica) sería oportuno apostar por medidas que sirvan de apoyo a estos sistemas más extensivos. Si bien el eje 2 del FEADER (Medio Ambiente y Desarrollo Rural) es el que mayores ayudas distribuye, éstas continúan siendo muy inferiores a las ayudas del FEAGA.

(vii) Sería igualmente necesario un mayor desacoplamiento de los pagos en las zonas donde los riegos se realizan con agua de acuíferos sobreexplotados. Es especialmente urgente que los pagos acoplados a la producción relacionados con el sector vitivinícola pasen a formar parte del Pago Único para disminuir la presión existente sobre las unidades hidrogeológicas de la cuenca alta del Guadiana.

(viii) Se recomienda la realización de evaluaciones periódicas del PEAG y de otros documentos administrativos que tratan de poner fin a la sobrepresión de las unidades hidrogeológicas analizando, además, el beneficio del desacoplamiento de las ayudas a la mayor producción agraria en el estado de los recursos hídricos.

Este trabajo confirma la importancia de mejorar las políticas de gestión del agua y reciclado con el fin de asegurar la disponibilidad futura de agua en un escenario con recursos hídricos decrecientes, y a la vez reducir las tensiones entre regiones y países (García-Ruiz et al., 2011). Esas políticas de gestión integrada de los recursos hídricos deben asegurar la mejora de la calidad del agua, la utilización sostenible de los recursos evitando sus sobreexplotación, y, paralelamente, asegurar la protección de los paisajes naturales sin que se resienta el bienestar de la población (López-Moreno et al., 2007).

\section{Referencias bibliográficas}

Álvarez-Cobelas, M., Cirujano, S., Sánchez-Carrillo, S. 2001. Hydrological and botanical man-made changes in the Spanish wetland of Las Tablas de Daimiel. Biological Conservation 97, 89-98.

Burke, S., Mulligan, M., Thomas, J.B. 1999. Optimal irrigation efficiency for maximum plant productivity and minimum water loss. Agricultural Water Management 40, 377-391.

Berzas, J.J., García, L.F., Rodríguez, L.C., Martín-Álvarez, P.J. 2000. Evolution of the water quality of a managed natural wetland: Tablas de Daimiel Natural Park (Spain). Water Research 34, 3161-3170.

CHG 2008. Plan Especial del Alto Guadiana. Anexo VII Memoria técnica. Disponible en: http:// www.chguadiana.es/?url=32\& corp=chguadiana\&lang=es.

CHG 2009a. Demarcación Hidrográfica del Guadiana. Plan Hidrológico 2009. Disponible en: http://www .chguadiana.es.

CHG 2009b. Capas SIG facilitadas por la Confederación Hidrográfica del Guadiana (comunicación directa). 
Cirujano, S., Casado, C., Bernués, M., Camargo, J.A. 1996. Ecological study of Las Tablas de Daimiel National Park (Ciudad Real, Central Spain): Differences in water physico-chemistry and vegetation between 1974 and 1989. Biological Conservation 75, 211-215.

CLM 2008. Programa de Desarrollo Rural de Castilla-La Mancha 2007-2013. Tomo II. Anexo I. Disponible en: http://www.jccm.es.

Cobelas, A., Sánchez-Soler, M.J., Carrasco, M., García Consuegra, B., Escuderos, J., ÁlvarezCobelas, M. 1996. Aspectos históricos. En Las Tablas de Daimiel, ecología acuática y sociedad, M.J. Álvarez-Cobelas, S. Cirujano (eds.), ICONA, Madrid, pp. 219-234.

Compés López, R. García Álvarez-Coque, J.M. 2009. La Reforma de la PAC del 2013 y estrategias para España. Observatorio de Política Exterior Española. Fundación Alternativas.

Conan, C., de Marsily, G., Bouraoui, F., Bidoglio, G. 2003. A long-term hydrological modelling of the Upper Guadiana river basin (Spain). Physics and Chemistry of the Earth 28, 193-200.

FEAGA 2010. Fondos Europeos Agrícolas FEAGA y FEADER. Informe mensual de pagos. Ejercicio 2010 (16/10/09 a 15/10/2010). Disponible en: http://www.feaga.es.

Fornés, J., Rodríguez, J.A., Hernández, N., Llamas, M.R. 2000. Possible solutions to avoid conflicts between water resources development and wetland conservation in the "La Mancha Húmeda" Biophere Reserve (Spain). Physics and Chemistry of the Earth 25, 623-627.

García Rodriguez, M., Llamas, M.R. 1992. Aspectos hidrogeológicos en relación con la génesis y combustión espontánea de las turbas en los "Ojos" del Guadiana. Actas del III Congreso Geológico de España y VIII Congreso Latinoamericano de Geología, Salamanca, Tomo 2, pp. 227-239.

García-Ruiz, J.M, López-Moreno, J.I., Vicente-Serrano, S.M., Lasanta-Martínez, T., Beguería, S. 2011. Mediterranean water resources in a global change scenario. Earth-Science Reviews 105, 121-139.

Giménez, R., Casalí, J., Chahor, Y. 2012. Herramientas informáticas de gestión de terrenos agrarios: potencialidades del modelo AnnAGNPS en Navarra. Cuadernos de Investigación Geográfica 38 (2), 107-121.

Holtz, G., Pahl-Wostl, C. 2012. An agent-based model of groundwater over-exploitation in the Upper Guadiana, Spain. Regional Environmental Change 12, 95-121.

IGME 2004. Informe número 4. Zonas húmedas Daimiel. Disponible en: http://www.igme.es.

JCCM 2009. Pagos. Disponible en: http://pagina.jccm.es/agricul/paginas/agricultura-ganaderia/ pagos.htm.

Kilsby, C.G., Tellier, S.S., Fowler, H.J., Howels, T.R. 2007. Hydrological impact of climate change on the Tejo and Guadiana Rivers. Hydrology and Earth System Sciences 11, 1175-1189.

López González, A. 2002. Los procesos de urbanización en un territorio agrario: La Mancha conquense. Actas del XI Coloquio de Geografía Rural. Los espacios rurales entre el hoy y el mañana. Universidad de Cantabria, Santander, pp. 379-388.

López-Moreno, J.I., Beguería, S., Vicente-Serrano, S .M., García-Ruiz, J.M. 2007. Influence of the North Atlantic Oscillation on water resources in central Iberia: Precipitation, streamflow anomalies, and reservoir management strategies. Water Resources Research 43, W09411. doi: 10.1029/2007WR00584.

López Sanz, G. 1999. Irrigated agriculture in the Guadiana River high basin (Castilla-La Mancha, Spain): environmental and socioeconomic impacts. Agricultural Water Management 40, 171-181.

Llamas, R. 1988. Conflicts between wetland conservation and groundwater exploitation: two case stories in Spain. Environmental Geology and Water Sciences 11, 241-251.

MARM 2009. Hojas 1T. Subdirección General de Estadística. Ministerio de Agricultura y Medio Rural y Marino. 
MARM 2010. Hojas 1T. Subdirección General de Estadística. Ministerio de Agricultura y Medio Rural y Marino.

Martínez-Santos, P., de Stefano, L., Llamas, M.R., Martínez-Alfaro, P.E. 2008. Wetland Restoration in the Mancha Occidental Aquifer, Spain: A Critical Perspective on Water, Agricultural, and Environmental Policies. Restoration Ecology 16, 511-521.

Martínez Vega, J., Navalpotro Jiménez, P., Cebrián, J.A., Romero Calcerrada, R. 1995. Repercusiones de la sobreexplotación de acuíferos y de la P.A.C en la sustentabilidad de la agricultura manchega. Estudios Geográficos 219, 337-369.

Navarro, V., García, B., Sánchez, D., Asensio, L. 2011. An evaluation of the application of treated sewage effluents in Las Tablas de Daimiel National Park, Central Spain. Journal of Hydrology 401, 53-64.

Peinado, M., Plaza Tabasco, J., Ruiz Pulpón, A.R., Sánchez López, L., Serrano de la Cruz, M.A. 2009. La Mancha y las lagunas de Ruidera. En Itinerarios geográficos y paisajes por la provincia de Ciudad Real, M. Peinado, J.L. García Rayego, E. González Cárdenas, A.R. Ruiz Pulpón (Coords.), Universidad de Castilla-La Mancha, Ciudad Real, pp. 17-88.

Pillet Capdepón, F. 2011. La Mancha. Transformaciones de un espacio rural. Celeste Ediciones, Madrid.

Romero Calcerrada, R., Martínez Vega, J. 1997. Transformaciones de usos y estructuras agrarias en La Mancha Occidental. Estudios Geográficos 228, 451-475.

Ruiz Pulpón, A.R. 2007. Tipología territorial de la agricultura de regadío en los municipios de la cuenca hidrográfica del Guadiana. Consejo Económico y Social de Castilla-La Mancha, Toledo, $487 \mathrm{pp}$.

Sanz Donaire, J.J., Díaz Álvarez, M.D., Sánchez Pérez de Évora, A. 1994. La Mancha: transformaciones forzadas de los humedales. Boletín de la A.G.E. 18, 39-61.

Seo/BirdLife y WWF España 2010a. Caso de Estudio: La Montaña Alavesa (Álava). Relación entre la Política Agraria Común y el Medio Ambiente en España. Disponible en: http://www.wwf.es.

Seo/BirdLife y WWF España 2010b. ¿Quien contamina cobra? Disponible en: http://www.wwf.es.

WWF España, Seo/BirdLife, Ojos del Guadiana Vivos, Greenpeace, Ecologistas en Acción 2006. Propuestas de los grupos ecologistas al Plan del Alto Guadiana.

Xu, H., Corte-Real, J., Quian, B. 2007. Developing daily precipitation scenarios for climate change impact studies in the Guadiana and Tejo basins. Hydrology and Earth System Sciences 11, 1161-1173. 